Document downloaded from:

http://hdl.handle.net/10251/51393

This paper must be cited as:

Vayá Pérez, I.; Lhiaubet-Vallet, VL.; Jiménez Molero, MC.; Miranda Alonso, MÁ. (2014). Photoactive assemblies of organic compounds and biomolecules: drug-protein supramolecular systems. Chemical Society Reviews. 43:4102-4122. doi:10.1039/C3CS60413F.

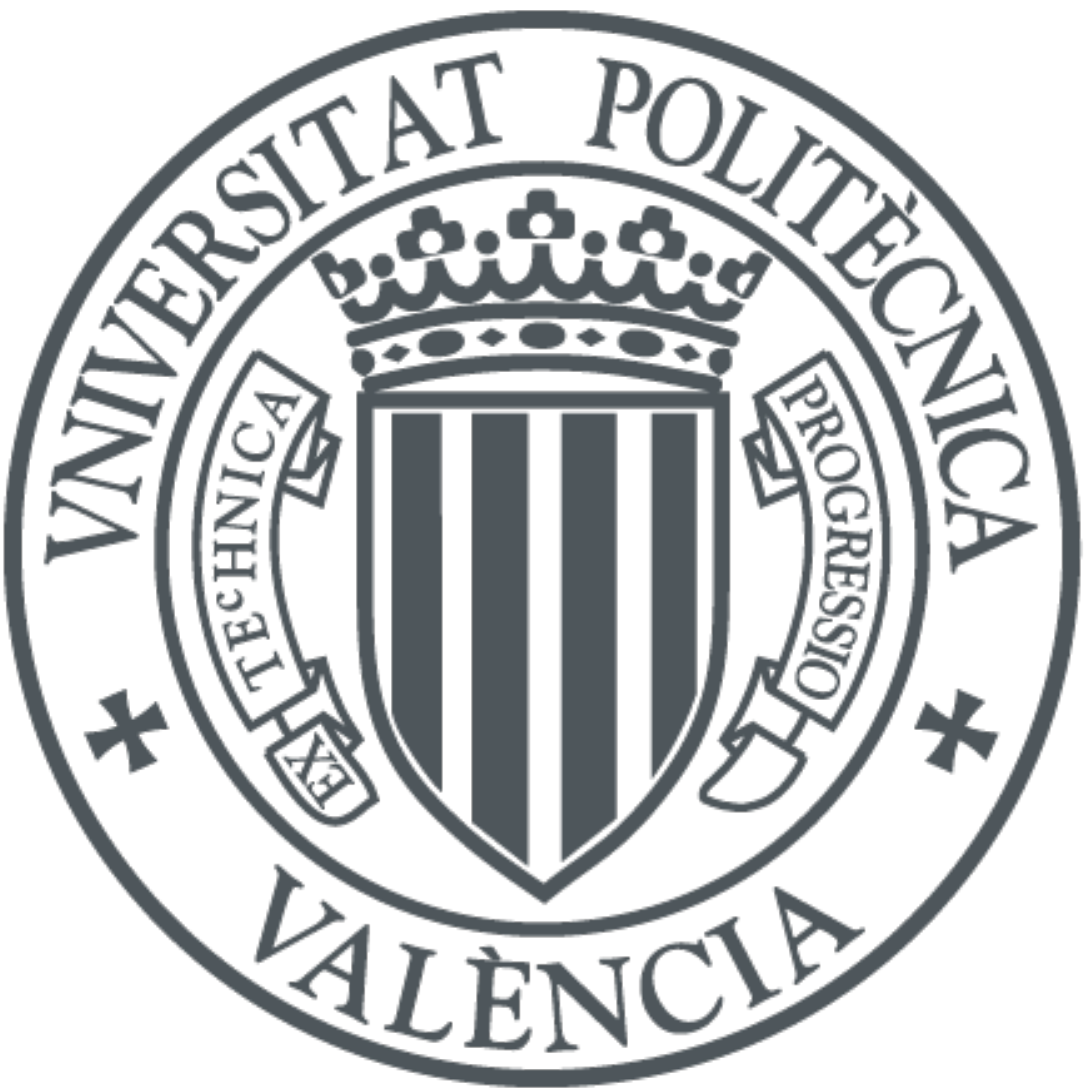

The final publication is available at

http://dx.doi.org/10.1039/C3CS60413F

Copyright Royal Society of Chemistry

Additional Information 


\section{Photoactive Assemblies of Organic Compounds and Biomolecules: Drug/Protein \\ Supramolecular Systems}

Ignacio Vayá, Virginie Lhiaubet-Vallet, M. Consuelo Jiménez* and Miguel A.

$$
\text { Miranda* }
$$

Departamento de Química/Instituto de Tecnología Química UPV-CSIC. Universitat Politècnica de València, Camino de Vera s/n, Apdo 22012, E-46071 Valencia (Spain). mcjimene@qim.upv.es; mmiranda@qim.upv.es

Keywords: $\alpha_{1}$-acid glycoproteins, fluorescence, laser flash photolysis, serum albumins, photoreactivity, protein binding.

Dedicated to the memory of Prof. Nicholas J. Turro 


\section{Abstract}

The properties of singlet and triplet excited states are strongly medium-dependent. Hence, these species constitute valuable tools as reporters to probe compartmentalised microenvironments, including drug@protein supramolecular systems. In the present review, the attention is focused on the photophysical properties of the probe drugs (rather than those of the protein chromophores) using transport proteins (serum albumins and $\alpha_{1}$-acid glycoproteins) as hosts. Specifically, fluorescence measurements allow investigating the structural and dynamic properties of biomolecules or their complexes. Thus, the emission quantum yields and the decay kinetics of the drug singlet excited states provide key information to determine important parameters such as the stoichiometry of the complex, the binding constant, the relative degrees of occupancy of the different compartments, etc. Application of the FRET concept allows determining donor-acceptor interchromophoric distances. In addition, anisotropy measurements can be related to the orientation of the drug within the binding sites, where the degrees of freedom for conformational relaxation are restricted. Transient absorption spectroscopy is also a potentially powerful tool to investigate the binding of drugs to proteins, where formation of encapsulated triplet excited states is favoured over other possible processes leading to ionic species ( $i$. e. radical ions), and their photophysical properties are markedly sensitive to the microenvironment experienced within the protein binding sites. Even under aerobic conditions, the triplet lifetimes of protein-complexed drugs are remarkably long, which provides a broad dynamic range for identification of distinct triplet populations or for chiral discrimination. Specific applications of the laser flash photolysis technique include the determination of drug distribution among the bulk solution and the protein binding sites, competition of two types of proteins to bind a 
drug, occurrence of drug-drug interactions within protein binding sites, enzymatic-like activity of the protein or determination of enantiomeric compositions.

The use of proteins as supramolecular hosts modifies the photoreactivity of encapsulated substrates by providing protection against oxygen or other external reagents, by imposing conformational restrictions in the binding pockets, or by influencing the stereochemical outcome. In this review, a selected group of examples is presented including decarboxylation, dehalogenation, nucleophilic addition, dimerisation, oxidation, Norrish type II reaction, photo-Fries rearrangement and $6 \pi$ electrocyclisation. 


\section{Introduction}

Transport proteins are very abundant in plasma and are responsible for a variety of relevant processes; ${ }^{1-4}$ one of their most important physiological roles is to carry different agents (i.e. drugs or metabolites) in the bloodstream for their selective delivery to specific targets. ${ }^{2,5}$ In this context, the binding of drugs to transport proteins is a key process, since it is involved in the modulation of drugs solubility in plasma, toxicity, susceptibility to oxidation, and in vivo half-life. ${ }^{2-4}$ For these reasons, protein binding has been studied for years with different techniques in order to understand their functions and to disclose the structural basis for designing new therapeutic agents. ${ }^{6}$

When drugs are bound to proteins, their time of action is prolonged by retarding metabolisation. The extent of binding depends on total drug concentrations and on its affinity to the protein. The process is usually reversible, and equilibrium is established between bound and free drug. Only unbound drugs are pharmacologically active, so a high protein binding affinity results in improved solubility and increased half-life. Conversely, a low binding affinity is associated with limited ability to perfuse tissues and to reach the site of action.

Human serum albumin (HSA) is synthesised and secreted by the liver. Its primary structure consists of a single chain of 585 amino acid residues, containing one tryptophan, 17 disulfide bridges, and one free cysteine. As much as $67 \%$ of the secondary structure is formed by a $\alpha$-helix of six turns; the three-dimensional structure can be described in terms of three domains, each of them constituted by two subdomains. ${ }^{7}$ Bovine serum albumin (BSA) is also among the most studied and commonly used proteins; it presents $76 \%$ sequence similarity to HSA, but contains two Trp residues instead of one. In general, the structural differences observed between both albumins are conservative in nature. Owing to the similarity between HSA and BSA, 
many studies on the drug-protein binding process have used BSA as a model. ${ }^{8-10}$ Usually, small organic molecules bind primarily to two high-affinity sites of albumins, with typical association constants in the range of $10^{4}-10^{6} \mathrm{M}^{-1}$. According to Sudlow's nomenclature, they are called site I and site II. ${ }^{11}$ In addition, lower-affinity sites are often populated.

Likewise, $\alpha_{1}$-acid glycoproteins are plasma transport proteins synthesised in the liver. They constitute one of the major types of acute phase proteins, and hence their serum concentration increases in response to a systemic tissue injury, inflammation or infection. In humans, HAG (human $\alpha_{1}$-acid glycoprotein) consists of one polypeptide chain with 183 amino acids and has a molecular weight of $44 \mathrm{kDa}$. This protein exhibits a high degree of glycosylation, with carbohydrates accounting for $\sim 45 \%$ of its total mass. For HAG, up to seven binding sites have been described; however, most small organic molecules bind almost exclusively to one of them. This high-affinity site is large and flexible, where the areas for basic, acid, and neutral drugs overlap. ${ }^{12-20}$ As regards the bovine analogue (BAG), binding of some ligands has been studied, and the results reveal substantial overlap of a basic drug and a steroid hormone binding sites, which significantly affect each other. The hydrophobic nature of the binding pockets on the two glycoproteins is similar; however, their microviscosities are markedly different. $^{21}$

In view of the importance of the drug-protein binding process, a number of techniques have been developed for investigation of this issue. They include equilibrium dialysis, HPLC, chromatography, ultrafiltration, spectrophotometry, calorimetry, circular dichroism, capillary electrophoresis, NMR, etc. ${ }^{22-33}$ The main limitations of these methodologies are related to sensitivity, interferences, diffusion 
problems or lack of reproducibility arising from a complicated workup. In the present review, the attention is focused on photophysical techniques, which combine steadystate and time-resolved fluorescence (including anisotropy experiments) with transient absorption spectroscopy. In addition, modified photoreactivity of some ligands encapsulated within protein binding sites is discussed.

As the review is dedicated to the memory of N. J. Turro, it is pertinent to say that he made relevant contributions in related fields. They encompass from chiral protein scissors to analysis of protein-surfactant interactions or singlet oxygen production within proteins. ${ }^{34-39}$

\section{Fluorescence studies}

Fluorescence spectroscopy is one of the most widely used analytical techniques in biochemistry and molecular biophysics, mainly due to its high sensitivity and capability to probe different microenvironments. Fluorescence measurements allow investigating the structural and dynamic properties of biomolecules or their complexes and can be performed in the steady-state or time-resolved modes. In the case of drug@protein systems, the excited state dynamics provides key information on fundamental processes such as energy or charge transfer, depending on the specific supramolecular interactions. Thus, characterisation of encapsulated singlet excited states constitutes an appropriate tool to investigate molecular recognition processes involved in drug transport, metabolism and pharmacological activity. From the emission quantum yields and the lifetimes of the singlet excited states of a bound ligand, it is possible to determine key parameters such as the stoichiometry of the complex, the binding constant or the degree of occupancy. Although changes in the intrinsic fluorescence properties of the tryptophan residues can be monitored, in this review we have focused 
our attention on the emission behaviour of probe drugs (Chart 1) when bound to a protein.

\subsection{Biphenyl derivatives}

The nonsteroidal antiinflammatory drug flurbiprofen (FBP) is a 2-arylpropionic acid, prescribed for the relief of mild to moderately severe pain and for ophthalmic disorders; ${ }^{40}$ FBP is usually commercialised as a racemic mixture, although its pharmacological effect is mainly due to the $(S)$-enantiomer. ${ }^{41}$ The emission profile of (S)-FBP@HSA upon excitation at 267 nm, where both FBP and HSA absorb, shows a spectrum with contribution of the individual components. However, the fluorescence intensity of the complex is lower than that calculated by taking into account the percentage of light absorbed by each subunit and assuming no interaction. ${ }^{42}$ Timeresolved measurements have been performed by fluorescence upconversion (FU) and time-correlated single photon counting (TCSPC). The FU kinetic traces at $310 \mathrm{~nm}$ (emission maximum of FBP) show that, beyond a few picoseconds, the decay of $(S)$ FBP@HSA is slightly faster than that of $(R)$-FBP@HSA. This is explained in terms of a dynamic quenching of bound FBP, which becomes even more pronounced at longer time scales as revealed by TCSPC. The nature of the observed quenching has been attributed to a stereoselective exciplex formation and/or electron transfer process. Timeresolved anisotropy measurements recorded by $\mathrm{FU}$ do not show significant configuration dependence for the encapsulated FBP; by contrast, the TCSPC anisotropy decays clearly show a chiral discrimination that can be related to the orientation of the drug within the protein, where the degrees of freedom for conformational relaxation can be more effectively restricted in the case of the $(R)$-enantiomer.

Photosolvolysis of FBP in aqueous solution gives rise to 2-(2-hydroxy-1,1'biphenyl-4-yl)propanoic acid (BOH) via a nucleophilic aromatic substitution. ${ }^{43}$ Being a 
phenolic compound, $\mathrm{BOH}$ is expected to display an enhanced acid character in the first singlet excited state, ${ }^{44}$ a property that can be employed to gather information on the nature of the microenvironment experienced within HSA. In the presence of increasing amounts of HSA, $(S)$-BOH gives rise to a ground-state complex with a maximum at $c a$. $300 \mathrm{~nm} \cdot{ }^{45}$ In neutral buffer, emission of BOH displays two maxima at 343 and $412 \mathrm{~nm}$, attributed to ${ }^{1} \mathrm{BOH}^{*}$ and to the corresponding excited phenolate, respectively. However, a progressive diminution of the $412 \mathrm{~nm}$ band is observed upon addition of protein, indicating that excited state deprotonation is disfavoured within the hydrophobic HSA cavities (Figure 1A). A similar trend is shown by $(R)-\mathrm{BOH}$, albeit to a significantly lower extent (Figure 1B). Displacement experiments with $(S)$-ibuprofen $((S)$-IBP), a site II probe, ${ }^{11}$ reveal that $\mathrm{BOH}$ mainly interacts within this binding site. Thus, fluorescence spectra show that displacement of $\mathrm{BOH}$ by $(S)$-IBP from the protein to the bulk solution leads to a recovery of the phenolate emission. A significant stereodifferentiation is observed for this process.

\subsection{Naphthalenes}

Naproxen (NPX) is a photosensitising nonsteroidal antiinflammatory drug containing a naphthalene chromophore, whose photobehaviour has been well characterised in homogeneous media. ${ }^{46}$ Upon excitation of the $(S)$-NPX@HSA complex at $266 \mathrm{~nm}$, where both protein and drug absorb, the emission profile exhibits contribution from the two components ${ }^{47}$ as well as a small but significant degree of energy transfer (EnT) from ${ }^{1}$ Trp* to NPX (Figure 2). The calculated interchromophoric distance assuming a FRET mechanism is $c a .24 \AA$. The behaviour of both $(S)$ - and $(R)$-NPX within HSA or BSA follows similar trends. When the NPX moiety is covalently bound to a cyclopeptide and encapsulated within HSA, EnT from ${ }^{1}$ Trp* to NPX is again observed in the complex. ${ }^{48}$ 
Cinacalcet $(\mathrm{CIN})$ is a calcimimetic $\operatorname{drug}^{49-51}$ that binds almost quantitatively to HSA $^{52}$ Upon complexation, emission of CIN@HSA roughly matches the spectrum simulated taking into account the relative absorption of the protein and free drug components. Thus, no energy transfer from ${ }^{1} \operatorname{Trp}^{*}$ to $\mathrm{CIN}$ has been demonstrated in the complex. ${ }^{53}$ The most remarkable photophysical properties from the biological point of view are associated with formation of the triplet excited state and are discussed in Section 3.2.

Encapsulation of 1'-hydroxy-2'-acetonaphthone (HAN) within HSA leads to enhanced fluorescence intensity and lengthening of the emission lifetimes. ${ }^{54}$ Picosecond anisotropy measurements show strong confinement in the protein microenvironment. Efficient energy transfer between ${ }^{1}$ Trp* and HAN (ca. 70\%) occurs in the HAN@HSA complex, with a calculated interchromophoric distance of $17 \AA$.

\subsection{Aromatic ketones}

Typically, aromatic ketones are non-fluorescent due to their high intersystem crossing quantum yields. However, the protein complexes of a few related compounds have been examined by means of fluorescence spectroscopy. This is the case of chalcones, some of which are flavonoids with antiinflammatory, antibacterial, antiviral, antitumor and antiparasitic activity. ${ }^{55}$ Licochalcone A (LCA) is a member of this family, whose interaction with HSA and BSA has been investigated. ${ }^{56,57}$ In homogeneous media, LCA displays three absorption maxima corresponding to the neutral (382 $\mathrm{nm})$, monoanionic (401 nm) and dianionic $(457 \mathrm{~nm})$ forms. In the presence of protein the spectrum is consistent with the predominance of the neutral LCA form and exhibits a large red shift, due to a strong drug-protein interaction. Enhancement of the LCA fluorescence intensity is accompanied by a progressive blue shift with increasing concentration of HSA or BSA. Time-resolved experiments reveal significant lengthening of the fluorescence 
lifetimes upon incorporation to HSA and BSA (5 and 3 times, respectively). The calculated docking of LCA in domain IIA of BSA is shown in Figure 3.

\subsection{Salicylic acids}

Salicylic acid (SLA) is known for its antiinflammatory activity due to inhibition of prostaglandins synthesis. ${ }^{58,59}$ This drug and many of its derivatives are also used for the treatment of skin diseases, such as inflammatory burns, psoriasis, etc. ${ }^{60-62} 2$-Hydroxy-4trifluoromethylbenzoic acid (HTB) is an active metabolite structurally similar to SLA derived from triflusal, a drug used in the treatment and prevention of various thromboembolic diseases. ${ }^{63}$ Upon excitation at $260 \mathrm{~nm}$ in the presence of HSA, the intrinsic protein fluorescence $\left(\lambda_{\max }=360 \mathrm{~nm}\right)$ is partially quenched by HTB, with a concomitant increase of the HTB band (405 nm), pointing to efficient energy transfer. This result is in agreement with expectations, taking into account the relative singlet state energies of Trp and HTB (96 and $80.7 \mathrm{kcal} \mathrm{mol}^{-1}$, respectively) and the considerable overlap between the emission of Trp and the absorption of HTB, which support the feasibility of a Förster mechanism. ${ }^{64}$

The bioactive compounds 3,5-dichlorosalicylic acid (DSA) and 5-chlorosalicylic acid (CSA) exhibit excited state intramolecular proton transfer (ESIPT), a photochemical process markedly influenced by the nature and strength of hydrogen bond interactions. This principle has found applications for the design of photostabilisers, solar filters, solar energy collectors, etc. ${ }^{65,66}$ More importantly, ESIPT probes have been used as molecular reporters for the microheterogeneous environments provided by a variety of biological and biomimicking assemblies. ${ }^{67-69}$ After ESIPT, both DSA and CSA tautomerise to their keto form, which is the only emitting species at $\sim 420$ nm. ${ }^{70,71}$ The absorption spectra of DSA and CSA are red-shifted in the presence of BSA, in agreement with the hydrophobic nature of the environment. ${ }^{72,73}$ Likewise, for 
DSA@BSA a slight red-shift of the fluorescence is observed, together with a significant quenching. By contrast, enhanced emission of the keto form of CSA is observed within BSA. The binding constant $\left(\mathrm{K}_{\mathrm{B}}\right)$ values determined by the modified Stern-Volmer ${ }^{74}$ and the Benesi-Hildebrand equations, ${ }^{75}\left(\mathrm{~K}_{\mathrm{B}}<10^{3} \mathrm{M}^{-1}\right)$ show in both cases a moderate binding to the proteins. Steady-state fluorescence anisotropy measurements are consistent with a higher degree of motional restriction in the confined environment provided by the protein.

Another SLA derivative, whose interaction with BSA has been recently addressed, is aurintricarboxylic acid (ATA), a red dye used as antiapoptotic drug. ${ }^{76}$ The fluorescence intensity of ATA is enhanced upon binding to BSA $\left(\mathrm{K}_{\mathrm{B}}>10^{5} \mathrm{M}^{-1}\right) ;^{.7}$ accordingly, time-resolved measurements show that the average lifetime $\left(\left\langle\tau_{\mathrm{F}}\right\rangle\right)$ increases from $1.23 \mathrm{~ns}$ in the bulk solution to 6.14 ns in ATA@BSA. ${ }^{78}$ This is attributed to the restricted confinement of the drug within the protein and is confirmed by steadystate and time-resolved anisotropy measurements.

\subsection{Heterobicyclic compounds}

Isofraxidin (ISF) is a coumarin derivative with antiinflammatory and antitumor activity. ${ }^{79}$ The fluorescence intensity of ISF increases in the presence of HSA; Scatchard plot analysis and molecular modelling point to preferential binding to site I, with a constant value in the order of $10^{5} \mathrm{M}^{-1}$. A similar behaviour is observed for formonometin (FME), a natural estrogenic compound with antioxidant properties. ${ }^{80}$ Binding to HSA leads to enhancement and blue shift of its fluorescence maximum; $K_{B}$ is also in the range of $10^{5} \mathrm{M}^{-1}$. As usually, fluorescence anisotropy measurements in the presence of HSA are in agreement with a more constrained environment provided by the protein cavity. 
Piroxicam (PIR) is a nonsteroidal antiinflammatory drug that binds to HSA at two sites. ${ }^{81}$ Singlet excited PIR decays within the protein cavities with time constants in the picosecond range. Upon excitation at the protein band, energy transfer from ${ }^{1} \operatorname{Trp} *$ to PIR is observed with moderate efficiency. Fluorescence anisotropy studies indicate diffusion of PIR within HSA.

Psoralens are widely used for the treatment of psoriasis and eczema. ${ }^{82}$ The fluorescence intensity of a number of psoralens and coumarins decreases and shifts to the blue upon addition of HSA $;^{83}$ this effect is more pronounced for psoralen@HSA than for coumarin@HSA complexes. Scatchard plots analysis evidences the existence of two classes of binding sites; this is further confirmed by time-resolved fluorescence measurements, which reveal the existence of two lifetime components in the decay kinetics.

Quinolone-like drugs are an important class of antimicrobials that produce photosensitivity disorders. ${ }^{84-86}$ An early member of this family is nalidixic acid (NAL), whose major vehicle in plasma is HSA. ${ }^{87}$ Binding of NAL to HSA or BSA occurs mainly at site II and results in quenching of the drug fluorescence; ${ }^{88}$ in addition, energy transfer from ${ }^{1} \mathrm{Trp}^{*}$ to NAL is observed. Fluoroquinolones (FLQs) are quinolone derivatives with improved pharmaco-toxicological profile. ${ }^{89}$ The association constants for binding of different FQs such as enoxacin (ENO), lomefloxacin (LOM), ofloxacin (OFL), norfloxacin (NOR) and ciprofloxacin (CIP) to HSA and BSA have been determined by fluorescence spectroscopy and range from $10^{2}$ to $10^{5} \mathrm{M}^{-1} \cdot{ }^{90,91}$ In this context, the results obtained by chromatography, capillary electrophoresis or ultrafiltration are in agreement with low affinities of FLQs to serum albumins $\left(\mathrm{K}_{\mathrm{B}}<10^{3}\right.$ $\left.\mathbf{M}^{-1}\right),{ }^{92,93}$ in line with recent work based on fluorescence and laser flash photolysis. ${ }^{90}$ 


\subsection{Tricyclic aromatics}

Carprofen (CPF) is another example of nonsteroidal antiinflammatory drug with in vivo photosensitising properties. ${ }^{46}$ Binding of $\mathrm{CPF}$ to serum albumins at 1:1 molar ratio occurs with very favourable association constants $\left(\mathrm{K}_{\mathrm{B}}>10^{6} \mathrm{M}^{-1}\right) .^{94} \mathrm{In}$ addition, a significant degree of energy transfer from ${ }^{1} \mathrm{Trp}^{*}$ to $\mathrm{CPF}$ is observed upon excitation at 266 nm. ${ }^{47}$ This process is more pronounced for CPF@BSA than for CPF@HSA. Based on the FRET theory, the average donor-acceptor distance values for the EnT process are ca. $21 \AA$. No significant differences are found in the photobehaviour of $(S)$ - or $(R)$-CPF within the protein.

The binding process of the water-compatible anthracene derivative 9anthraceneacetic acid (ANA) to HSA and BSA, as well as to HAG and BAG has been systematically investigated. ${ }^{95}$ Analysis of the UV-vis absorption spectra suggests in all cases formation of 1:1 complexes between ANA and proteins. Fluorescence measurements $\left(\lambda_{\text {exc }}=367 \mathrm{~nm}\right)$ show a progressive decrease of the ANA emission intensity (390-470 nm) upon addition of increasing amounts of protein; this effect is more pronounced for ANA@HSA. However, the fluorescence lifetime of ANA in airequilibrated solutions ( $c a .10 .5 \mathrm{~ns}$ ) does not depend on the presence of protein. The binding constants determined by titration of the ANA emission upon addition of protein are slightly higher for glycoproteins than for albumins; in the former, only one binding site is considered $\left(\mathrm{K}_{\mathrm{B}} \sim 2 \times 10^{6} \mathrm{M}^{-1}\right)$, while in the latter two binding sites with different affinities are found $\left(\mathrm{K}_{\mathrm{BI}} \sim 10^{6} \mathrm{M}^{-1}\right.$ and $\left.\mathrm{K}_{\mathrm{BII}} \sim 10^{4} \mathrm{M}^{-1}\right)$. This is confirmed by displacement experiments with warfarin (site I probe) and IBP (site II probe). Similar trends are observed with the two enantiomers of 2-(9-anthracenyl)propanoic acid (ANP), although in this case a significant stereodifferentiation is noticed in the emission behaviour of the ANP@HSA complexes (Figure 4). ${ }^{96}$ 
A related anthracene derivative (2-anthracenecarboxylic acid, ANC) gives also rise to complexes with HSA and BSA. ${ }^{97-101}$ Fluorescence measurements on equimolar ANC/protein mixtures reveal formation of complexes with a 1:1 stoichiometry. The highest affinity site for ANC is attributed to site II in both proteins; the binding constant is larger for HSA $\left(\mathrm{K}_{\mathrm{B}} \sim 10^{8} \mathrm{M}^{-1}\right)$ than for BSA $\left(\mathrm{K}_{\mathrm{B}} \sim 10^{7} \mathrm{M}^{-1}\right)$. At high ANC/albumin ratios several binding sites are populated, and in some of them more than one ANC unit is accommodated. This can be monitored by fluorescence spectroscopy, through an enhancement of the emission intensity and loss of the vibrational fine structure. These changes have been discussed in connection with the stereochemical outcome of ANC photodimerisation within the protein cavities. Time-resolved fluorescence measurements at low ANC/albumin ratios reveal the presence of two lifetime components (1.8 and 4 ns), whereas at higher ANC concentration longer components appear with lifetimes closer to ANC in the bulk solution (15.8 ns). Fluorescence anisotropy measurements are consistent with a restricted rotational mobility of ANC within the protein binding sites.

Acridine-based drugs, such as acridine yellow (ACY) and cationic proflavin (PFL), can be used as photosensitisers for the treatment of cancer and other diseases. ${ }^{102}$ Both ACY and PFL form ground-state complexes with HSA, ${ }^{103}$ with association constants $\left(\mathrm{K}_{\mathrm{B}} \sim 10^{5} \mathrm{M}^{-1}\right)$ slightly higher for PFL than for ACY. Dynamic quenching of the HSA emission through EnT from Trp to PFL or ACY is accompanied by enhancement of the drug fluorescence; this process is more efficient for PFL@HSA than for ACY@HSA.

$\beta$-Carbolines are natural products with varied biological properties, including their interaction with neurotransmitters and neuromodulators of the central nervous system ${ }^{104}$ and their ability to photosensitise fungi, viruses or bacteria for photodynamic therapy. ${ }^{105}$ 
Harmane (HAR) and norharmane (NOR) are members of this family, whose binding properties to HSA and BSA have recently been addressed. ${ }^{106,} 107$ In neutral aqueous solution, NOR and HAR present two absorption maxima corresponding to the neutral $(\sim 348 \mathrm{~nm})$ and protonated $(\sim 370 \mathrm{~nm})$ species. ${ }^{108}$ The fluorescence intensity of protonated NOR $\left(\lambda_{\max } \sim 450 \mathrm{~nm}\right)$ or HAR $\left(\lambda_{\max } \sim 435 \mathrm{~nm}\right)$ markedly decreases upon addition of increasing amounts of albumins, with the concomitant enhancement of a new band at $\sim 380 \mathrm{~nm}$, corresponding to the neutral forms. Fluorescence measurements show that NOR binds more tightly to HSA $\left(\mathrm{K}_{\mathrm{B}} \sim 10^{5} \mathrm{M}^{-1}\right)$ than to BSA $\left(\mathrm{K}_{\mathrm{B}} \sim 10^{4} \mathrm{M}^{-1}\right)$; the association constant of HAR to BSA $\left(\mathrm{K}_{\mathrm{B}} \sim 10^{3} \mathrm{M}^{-1}\right)$ is much weaker. Fluorescence anisotropy studies on NOR@albumin also show a marked increase of the neutral species $\left(\lambda_{\max } \sim 380 \mathrm{~nm}\right.$ ) as a result of protein binding; this effect is higher for BSA.

\subsection{Miscellaneous compounds}

The importance of ligand/protein interactions is not only limited to the study of drugs, but can be extended to other systems such as natural bile acids whose binding to serum albumins is an important step in enterohepatic circulation. ${ }^{109}$ Cholic acid (CHA) is one of the primary metabolites synthesised from cholesterol in the liver; it is in part conjugated to glycine or taurine and plays a pivotal role in fat digestion. A remarkable emission enhancement, accompanied by a hypsochromic shift of the maximum ( $c a .50$ $\mathrm{nm}$ ) is observed upon binding of several dansyl (DNS)-labelled CHA (3 $\alpha$-DNS-CHA, $3 \beta$-DNS-CHA, $7 \alpha$-DNS-CHA and $7 \beta$-DNS-CHA) to HSA; ${ }^{110}$ this effect is more marked for the $\mathrm{C}-3$ regioisomers (Figure 5A, B). Two binding constants (in the order of $10^{5}$ and $10^{4} \mathrm{M}^{-1}$ ) are determined for $3 \alpha$ - and $3 \beta$-derivatives, whereas only one has been reported for $7 \alpha$ - and $7 \beta$-DNS-CHA $\left(c a .10^{4} \mathrm{M}^{-1}\right)$. Moreover, the $\alpha$-derivatives display stronger binding to the protein than the $\beta$-analogues. Experiments with site I and site II displacement probes demonstrate that $3 \alpha$ - and $3 \beta$-DNS-CHA selectively bind to site II, 
while $7 \alpha$ - and $7 \beta$-DNS-CHA populate site I of HSA. Time-resolved measurements reflect a significant increase of the fluorescence lifetimes, attributed to a less efficient deactivation by non-radiative processes. This might be due to restrictions of the freedom degrees inside the HSA binding sites, where the microenvironment protects the singlet excited state from attack by deactivating species. The singlet decay kinetics has been used to determine the distribution of DNS-CHA between the bulk solution and the HSA binding sites; the results are in agreement with the trends observed in the steady-state experiments. An EnT process from ${ }^{1} \mathrm{Trp}^{*}$ to the DNS-derivatives is observed (Figure 5C), with interchromophoric distances of 21 and $25 \AA$ for the C-3 and C-7 regioisomers, respectively. Docking studies are in agreement with the different binding behaviour of the dansyl derivatives. Figure 6 shows the minimum energy conformation of interaction between $3 \beta$-DNS-CHA (balls) and site 1 of HSA (sticks).

The fluorescence intensity and the average lifetime of the antibiotic tetracycline hydrochloride $(\mathrm{TCH})$ increase upon binding to HSA, BSA and alkaline phosphatase (ALP) from Escherichia coli; this effect is higher for ALP. ${ }^{69,70,111,112}$ Quenching of Trp emission is observed, with concomitant enhancement of the drug fluorescence intensity, as a result of the EnT process. Binding constants in the $10^{6} \mathrm{M}^{-1}$ range are determined for ALP, whereas for albumins the values are two orders of magnitude lower. Time-resolved anisotropy measurements point to a motional restriction of the drug within the protein cavity. The higher correlation time obtained for HSA suggests a more buried location of the drug within this protein, which is confirmed by molecular docking studies.

Squaraine dyes (SQD) are fluorescent sensors with technological and biological applications. ${ }^{113,114}$ Binding of the parent compound as well as its tetrabromo (SQB) and tetraiodo (SQI) derivatives to HSA and BSA has been monitored by the absorption 
spectral changes, characterised by large red-shifts and hypochromism. ${ }^{115,}{ }^{116}$ The 1:1 dye@protein complexes are formed with association constants of about $10^{6} \mathrm{M}^{-1}$ for SQD and SQB, and $c a \cdot 10^{5} \mathrm{M}^{-1}$ for SQI. The emission spectra of the dyes increase dramatically and shift to the red upon addition of albumins; this is accompanied by significantly longer lifetimes. Displacement experiments with site-specific binding probes evidence that SQB and SQI preferentially bind to site II, while SQD binds at both sites, with a marginal selectivity for site II.

Levosimendan (LSM) is a cardiovascular drug with a strong inotropic effect used for acute heart failure. ${ }^{117}$ Upon binding to HSA, 1:1 stoichiometry complexes are formed with association constants of $\sim 10^{6} \mathrm{M}^{-1} \cdot{ }^{118}$ The UV absorption spectrum of LSM@HSA is red-shifted, suggesting an increase in the electronic conjugation due to a more planar conformation of the drug upon encapsulation. Femtosecond fluorescence upconversion measurements show a clear enhancement of about three times of $\left\langle\tau_{\mathrm{F}}\right\rangle$ of LSM bound to HSA.

Lumichrome $(\mathrm{LCH})$, the major riboflavin biodegradation product, has some natural biological functions, ${ }^{119}$ and is able to generate singlet oxygen. ${ }^{120,}{ }^{121}$ Upon addition of HSA, the UV-absorption maximum of LCM (355 nm) does not show noticeable changes, while the emission intensity (maxima at $475 \mathrm{~nm}$ ) decreases. Job's plot analysis evidences the formation of a 1:1 complex between $\mathrm{LCH}$ and the protein, with an association constant in the order of $10^{4} \mathrm{M}^{-1}$. Time-resolved anisotropy measurements are consistent with the heterogeneity of LCH binding to HSA, where the rotational relaxation time of the drug is much lower than that of the global rotational time of the protein.

Upon interaction of tropolone derivatives with anticancer effects, including colchicine (COL) and colchiceine (CEI) with HSA, a significant enhancement of the 
CEI fluorescence is noticed, in contrast to the nearly negligible effect observed for COL. ${ }^{122}$ The association constant for CEI@HSA determined by fluorescence measurements is in the order of $10^{4} \mathrm{M}^{-1}$; conversely, for COL, the estimated $\mathrm{K}_{\mathrm{B}}$ value is below $10^{3} \mathrm{M}^{-1}$. Immobilisation of the tropolone chromophore within the specific binding site of the protein is assumed to be the main factor responsible for fluorescence enhancement, as in the interaction between COL and tubulin protein. Displacement experiments reveal selective binding to site II of HSA.

\section{Transient absorption spectroscopy}

Laser flash photolysis has been less exploited than fluorescence emission to investigate the binding of ligands to proteins, although it is also a potentially powerful tool. Here, we will focus on the behaviour of triplet excited states of ligands (Chart 1) generated upon LFP, following protein encapsulation. It will be shown that the properties of these transient species (especially the triplet lifetimes, $\tau_{\mathrm{T}}$ ) are very sensitive to the microenvironment experienced within the protein binding sites. Hence, they can be successfully used to investigate the issue of drug binding, providing information on interaction strength, conformational restrictions, protection from attack by oxygen or other reagents, stereochemical requirements, etc. Applications of the LFP technique to drug/protein systems are detailed below. They include a variety of issues, such as the determination of drug distribution among the bulk solution and the protein binding sites, competition of two proteins to bind a ligand, drug-drug interactions within protein binding sites, enzymatic-like activity of serum albumin or determination of enantiomeric compositions.

\subsection{Biphenyl derivatives}

The transient absorption spectrum of $(S)$-FBP in PBS solution obtained after laser excitation at $266 \mathrm{~nm}$, under air, displays a maximum at $360 \mathrm{~nm}$, assigned to the FBP 
first triplet excited state $\left({ }^{3} \mathrm{FBP}^{*}\right) .{ }^{123}$ The kinetic decay trace follows a first order exponential law with a lifetime $\left(\tau_{\mathrm{F}}\right)$ of $1.5 \mu \mathrm{s}$ (Eq. 1). After addition of HSA at $0.7: 1$ drug/protein molar ratio, ${ }^{3} \mathrm{FBP} *$ is again the only transient species detected; however, two monoexponential terms are necessary to fit accurately the decay trace (Eq. 2), with lifetimes of 11.2 (minor) and $35.9 \mu$ s (major). They are ascribed to ${ }^{3} \mathrm{FBP}^{*}$ within site I $\left(\tau_{\mathrm{I}}\right)$ and site II $\left(\tau_{\mathrm{II}}\right)$ of HSA, respectively, based on the higher affinity of FBP for site II. $^{124}$ To obtain independent evidence supporting this assignment, LFP experiments have been performed in the presence of $(S)$-IBP as site II-probe. ${ }^{125}$ Thus, addition of $(S)$ IBP to the $(S)$-FBP/HSA mixtures results in a decreased contribution of the longest lifetime term, with a concomitant enhancement of the components assigned to free and site-I-bound FBP. For a battery of solutions at different $(S)$-FBP/HSA molar ratios (from 1.4:1 to $1: 1$ ), fitting of the decay traces contains three monoexponential terms (Eq. 3), supporting distribution of the drug among the two protein binding sites and the bulk solution. From the corresponding preexponential coefficients $A_{F}, A_{I}$ and $A_{I I}$ the percentage of $(S)$-FBP bound to different amounts of HSA or BSA can be determined. The distribution of $(S)$-FBP among the binding sites and the bulk solution is represented in Figure 7. At high $(S)$-FBP/HSA molar ratios most of the acid remains unbound, whereas at low $(S)$-FBP/HSA molar ratios site II is selectively populated. The work has been extended to $(R)$-FPB and to BSA. ${ }^{123}$ The most significant differences between both albumins are related to the dynamic ranges found for the triplet lifetimes and to the relative occupancy of the two binding sites. Lengthening of the $\tau_{\mathrm{T}}$ values is partially due to protection of ${ }^{3} \mathrm{FBP}^{*}$ from attack by oxygen when encapsulated. Thus, the rate constant of triplet quenching by oxygen for free $(S)$-FBP in PBS is $1 \times 10^{10} \mathrm{M}^{-1} \mathrm{~s}^{-1}$; by contrast, the values in site I or site II are one and two orders of magnitude lower, respectively. 
A similar study has been performed on FBP-Me, the methyl ester of FBP; the hydrophobic character of this prodrug favours inclusion within HSA. ${ }^{126,127}$ Aqueous solutions containing $(S)$-FBP-Me and HSA (molar ratio from 10:1 to 0.5:1) give rise to the transient absorption spectra assigned to ${ }^{3} \mathrm{FBP}-\mathrm{Me}^{*}$ (Figure $8 \mathrm{~A}$ ). For $(S)$-FBPMe/HSA ratios between 1:1 and 0.5:1, the signal follows a second-order exponential decay with lifetimes of 31.5 and $4.1 \mu$ s. Based on the higher affinity of 2-arylpropionic acids methyl esters for site $\mathrm{I}^{128}$ the major component under non-saturating conditions (with longer $\tau_{\mathrm{T}}$ ) is assigned to $(S)$-FBP-Me within this site; consequently, the minor component is assigned to site II-bound FBP-Me. Independent evidence supporting this assignment is obtained by LFP experiments in the presence of warfarin, as site I probe. ${ }^{129}$ Thus, at 1:1:1 (S)-FBP-Me/HSA/warfarin molar ratio the contribution of the longer-lifetime component drops to $c a .50 \%$ (as compared with $c a$. $70 \%$ in the absence of warfarin). In the case of $(R)$-FBP-Me, the triplet lifetimes within site I and II are 157.6 and $16.6 \mu$ s, respectively, indicating a remarkable stereodifferentiation in the decay kinetics within the protein microenvironment (Figure 8B). In BSA, the most remarkable difference is found under non-saturating conditions; thus, for 1:1 FBPMe/albumin molar ratio, $20-30 \%$ of the drug remains free (compared to complete binding in HSA).

The behaviour of FBP and FBP-Me in the presence of HAG and BAG has been studied with a similar methodology. ${ }^{130}$ Only one $\tau_{\mathrm{T}}$ value clearly higher than that of free FBP or FBP-Me is found in the presence of glycoproteins, indicating only one type of binding site. The percentages of free and protein-bound ligand obtained by fitting the decay traces with Eq. 4 indicate that FBP binds weakly to both glycoproteins, while FBP-Me is more efficiently included, specifically in BAG. 
The glucuronide FBP-Gluc is a phase II metabolite of FBP. ${ }^{131}$ Even at low FBPGluc/HSA molar ratios, a high amount of glucuronide remains unbound to the protein, in good agreement with an enhanced hydrosolubility of this metabolite, which facilitates its elimination. No stereodifferentiation is observed in the protein-binding process, and only one type of microenvironment is occupied by $(2 S)$ - and (2R)-FBP-Gluc (triplet lifetime $c a .25 \mu$ s), unlike the case of parent FBP. Displacement experiments using $(S)$ IBP as specific site II probe confirm selective occupancy of this site. ${ }^{132}$

In the case of the main photoproduct of $(S)$-FBP in aqueous media, $(S)$-BOH, the transient absorption spectrum consists of a broad band centred at $380 \mathrm{~nm}$, attributed to ${ }^{3} \mathrm{BOH}^{*}$. A dramatic enhancement of the triplet lifetimes within HSA has been observed (19.0 $\mu$ s, compared with $1.3 \mu$ s in bulk PBS). ${ }^{45}$ The study has also been performed with $(R)-\mathrm{BOH}$, and no stereodifferentiation has been noticed in this case.

A new methodology for a rapid and reliable assessment of drug distribution between two proteins present simultaneously in a biological medium is based on determination of the relative contributions of the triplet lifetimes components obtained from the decay curves in the presence of serum albumin/glycoprotein binary systems. ${ }^{130}$ Thus, the decay traces obtained at $360 \mathrm{~nm}$ for a $\operatorname{FBP}(\mathrm{Me}) /$ serum albumin/glycoprotein mixtures at 1:0.5:0.5 molar ratio are fitted assuming that four different kinds of triplets can be present (Eq. 5). They are ascribed to $\mathrm{FBP}(\mathrm{Me})$ free, bound to glycoprotein and within site I or site II of albumins. The results show that albumins are always the major carriers for FBP; whereas in the case of FBP-Me, BAG competes favourably with BSA when both proteins are present in the same medium.

Determination of enantiomeric compositions, based on transient absorption spectroscopy, has also been achieved by exploiting the stereodifferentiation of triplet lifetimes within serum albumins for chiral recognition. ${ }^{133}$ The procedure involves LFP 
of a series of solutions containing mixtures of the $(S)$ - and $(R)$-enantiomers (percentages from 0:100 to 100:0) in the presence of equimolar amounts of the appropriate serum albumin (see Figure 9A for FBP-Me in the presence of HSA). To obtain accurate fittings, it is assumed that four different kinds of triplets are present, ascribed to $(R)$ - and (S)-FBP-Me within site I and site II (Eq. 6). Assuming that the ratios $\mathrm{A}_{I}^{S} / \mathrm{A}_{I I} S$ and $\mathrm{A}_{I}^{R} /$ $\mathrm{A}_{\mathrm{II}}{ }^{\mathrm{R}}$ remain constant, fitting of the decay traces leads to the percentage of both enantiomers. A plot of the LFP-determined against known real values for FBP-Me in HSA (Figure 9B) clearly validates the proposed methodology. Chiral discrimination in the triplet lifetimes of the drug/protein complexes is the only requirement for the successful application of this LFP-based methodology, which may not be fulfilled in a number of systems. ${ }^{133}$ For example, the triplet lifetimes of $(S)$ - and $(R)$-FBP in the presence of HSA are too close, and hence the obtained values for the percentages of the two enantiomers are not reliable. The problem can usually be circumvented by choosing another protein where the triplet lifetimes of the two enantiomers are different enough. For FBP, bovine serum albumin (BSA) provides an appropriate chiral selector. Thus, when the decay traces obtained in the presence of BSA for different $(S)$-FBP/ $(R)$-FBP ratios are processed as before, good correlations are found between the LFP determined and the real enantiomeric compositions.

The LFP technique has also proven to be a powerful tool for in situ determination of the glucuronidase activity of HSA. This has been achieved by monitoring the hydrolysis of two steroisomeric flurbiprofen glucuronides back to parent FBP. ${ }^{132}$ The FBPGluc/HSA mixtures are incubated during regular time intervals at $37^{\circ} \mathrm{C}$; regression analysis to fit the triplet decays leads to a set of four lifetimes (for free and bound FBPGluc and for FBP within site I and site II, see Eq. 7). 


\subsection{Naphthalenes}

Naphazoline (2-(1-naphthylmethyl)imidazoline, NPZ) is a sympathomimetic agent with alpha adrenergic activity. After LFP of NPZ $\left(\lambda_{\text {exc }}=308 \mathrm{~nm}, \mathrm{~N}_{2}\right)$ in the presence of BSA, protein-bound ${ }^{3} \mathrm{NPZ}^{*}$ is detected at $410 \mathrm{~nm}$, with a lifetime of $c a .170 \mu \mathrm{s} .{ }^{134}$

The excited states of the $(R)$-enantiomer of CIN have been characterised in order to obtain relevant information about its complexation with HSA. ${ }^{53}$ Upon LFP of $(R)$ CIN@HSA $\left(\lambda_{\text {exc }}=308 \mathrm{~nm}\right.$, air), naphthalene-like triplet excited states are generated, with maxima at $420 \mathrm{~nm}$. The corresponding decays are satisfactorily fitted using a function containing two monoexponential terms, corresponding to a short-lived (8 $\mu \mathrm{s})$ and a long-lived (37 $\mu$ s) components different from the value found in pure PBS (1.9 $\mu \mathrm{s})$, indicating that the drug is incorporated into two different binding sites of HSA. Estimation of the $\mathrm{K}_{\mathrm{B}}$ by LFP at $\lambda_{\mathrm{exc}}=266 \mathrm{~nm}$ leads to an average value in the order of 6 $\times 10^{5} \mathrm{M}^{-1}$. From the intensity of the triplet signal immediately after the laser pulse, an intersystem crossing quantum yield of 0.56 is determined for $(R)$-CIN@HSA. To investigate triplet quenching by oxygen in the protein microenvironment, $(R)$ CIN@HSA has been submitted to chemical deoxygenation by addition of sodium sulphite. Despite the long triplet lifetimes of the complex, the rate constant of quenching by oxygen $\left(5.4 \times 10^{7} \mathrm{M}^{-1} \mathrm{~s}^{-1}\right)$ is 2 orders of magnitude lower than that determined in the bulk solution, which is due to the relative slower diffusion rates in the microheterogeneous system. As a consequence, the singlet oxygen quantum yield inside the protein is nearly negligible, while its value is $\phi_{\Delta}=0.35$ in homogeneous aqueous media. The main finding after encapsulation is that the protein microenvironment protects the drug from attack by oxygen, preventing the phototoxic effects caused by formation of singlet oxygen. This results in an enhanced photosafety of the drug. Interestingly, $(R)$-CIN exhibits also a significant affinity towards glycoproteins, where 
the drug is located in the only existing binding site, with triplet lifetimes of $15 \mu \mathrm{s}$ (HAG) and $20 \mu \mathrm{s}$ (BAG). The studies have been extended to (S)-CIN, which exhibits somewhat different triplet lifetimes.

Likewise, upon LFP at $308 \mathrm{~nm}$ of $(S)$ - or $(R)$-propranolol (PPN, a non-selective beta blocker used for the treatment of hypertension), the transient spectrum shows contributions due to ${ }^{3} \mathrm{PPN}^{*}$ and the radical cation $\left(\mathrm{PPN}^{+\cdot}\right) .{ }^{135}$ From the decay traces monitored at $420 \mathrm{~nm}$ under aerobic conditions, their lifetimes have been determined as 1.9 and $13.5 \mu \mathrm{s}$, respectively. The spectra in the presence and in the absence of albumins are almost coincident, which is in good agreement with negligible PPN binding to these proteins. However, in the presence of glycoproteins, the kinetics are markedly different: the decay traces lengthen and require a function containing three monoexponential terms (Eq. 8) for a satisfactory fitting, corresponding to two free species $\left({ }^{3} \mathrm{PPN}^{*}\right.$ and $\left.\mathrm{PPN}^{+\cdot}\right)$ plus the longer lived protein-bound triplet. Regression analysis of the decay curves for different PPN/glycoproteins mixtures leads to the preexponential factors and hence to the amount of free and bound PPN. A remarkable species dependence is observed for both PPN enantiomers, with a clearly higher binding capability in the case of the bovine protein. Thus, at 1:1 drug/protein molar ratio a $45 \%$ of $(R)$-PPN is bound to HAG, while in the case of BAG this value is $76 \%$.

Nabumetone (4-[6-methoxy-2-naphthy1]-2-butanone, NAB) is a neutral nonsteroidal antiinflammatory drug. It binds to serum albumins and acts as prodrug, being metabolised by the liver to 6-methoxy-2-naphthylacetic acid, the active pharmacological form. ${ }^{136}$ After LFP $\left(\lambda_{\text {exc }}=337 \mathrm{~nm}, \mathrm{~N}_{2}\right)$ in the presence of BSA, bound ${ }^{3} \mathrm{NAB}^{*}$ is detected, with a lifetime of $c a .700 \mu \mathrm{s} .{ }^{137}$ No other transients are observed. Binding to HAG and BAG has also been investigated after LFP at $308 \mathrm{~nm}$ under air; protein bound ${ }^{3} \mathrm{NAB}^{*}$ decays with a $\tau_{\mathrm{T}}$ value of 16.6 in $\mathrm{HAG}$ and $25.8 \mu$ s in BAG. 
The photobehaviour of $(S)$ - and $(R)$-NPX in the presence of HSA or BSA has been investigated by LFP at $308 \mathrm{~nm}$ in PBS/air. ${ }^{130}$ The transient spectrum in the absence of protein shows the main maximum at $440 \mathrm{~nm}\left({ }^{3} \mathrm{NPX}^{*}, 1.8 \mu \mathrm{s}\right)$ and a weaker band in the 550-650 nm range $\left(\mathrm{NPX}^{+\cdot}\right)$. However, in the presence of sufficient amounts of albumins, only ${ }^{3} \mathrm{NPX} *$ is observed, with the kinetic traces at 440 decaying at longer timescales. At 1:1 molar ratio, a satisfactory fitting is obtained considering two monoexponential terms (Eq. 2), whereas at higher drug/protein ratios, three lifetime values are necessary to obtain a good fitting of the decay signal (Eq. 3). This is ascribed to the presence of two long-lived NPX@HSA species, in addition to free NPX. From the decay curves for NPX/protein ratios from 1:0.15 to 1:1 the values of the preexponential coefficients are determined, corresponding to free, site-I bound, and siteII-bound drug. By contrast, a different behaviour is observed in the presence of HAG or BAG, where the binding degree is markedly lower. ${ }^{130}$ Thus, with equimolar amounts of glycoproteins, two triplet lifetimes are found (Eq. 4), corresponding to free and bound drug. Regression analysis of the decay curves leads to the binding degree. Remarkable species dependence for both NPX enantiomers is noticed, with a clearly higher binding capability displayed by the bovine protein. Thus, at 1:1 drug/protein molar ratio a $19 \%$ of $(S)$-NPX is bound to HAG, while in the case of BAG this value is $57 \%$.

The interaction between HSA and two bioconjugates, which contain $(S)$ - or $(R)$ NPX covalently bound to a cyclopentapeptide with an arginine-glycine-aspartate sequence (cRGD), has also been studied using LFP. ${ }^{48}$ The results have been compared with those obtained for appropriate models. Excitation of NPX-cRGD bioconjugates at $266 \mathrm{~nm}$, under air, leads to the NPX triplet, with monoexponential decays ( $\tau_{\mathrm{T}} c a .60 \mu \mathrm{s}$ ) which strongly agrees with selective binding to one site. 
Three drugs containing the naphthalene chromophore, (NPX, PPN, and CIN) but with different affinities toward albumins and glycoproteins, have been employed for the assessment of drug distribution in binary protein systems, using a similar methodology as in the case of FBP and FBP-Me. ${ }^{135}$ Upon LFP of NPX, PPN and CIN in the presence or absence of proteins, the naphthalene triplet excited state at $420 \mathrm{~nm}$ is always detected, although the decay kinetics is structure-, medium- and species dependent. Experiments performed in both human (HSA/HAG) and bovine protein media (BSA/BAG) show that when two proteins are present simultaneously in the same medium, fitting of the decay traces is clearly consistent with a distribution of the drug between the different biological compartments and the bulk solution, which correlates well with the known protein affinities of each drug. The results demonstrate that albumins are the major carriers for NPX, whereas PPN binds preferentially to glycoproteins. An intermediate situation is found for CIN, which presents comparable affinity for both types of proteins (see Figure 10 for $(R)$-CIN)). The two enantiomers of each drug exhibit similar trends, although a small stereodifferentiation is observed between the triplet lifetimes in the protein binding sites.

The feasibility of drug-drug interactions (DDI) within the binding sites of transport proteins has been probed, using drug pairs (CIN/PPN and CIN/NAB) complexed within HAG or BAG. ${ }^{137}$ The concept involves detection of triplet-triplet energy transfer (TTEnT), which requires a close proximity between the donor and acceptor partners and can only occur within a common biological compartment. In the absence of glycoproteins, the drug mixtures are not soluble in PBS and give rise to turbid suspensions. Complexation of CIN/PPN and CIN/NAB with glycoproteins is easily followed by naked eye, through a complete solubilisation that leads to clear preparations. When a solution of CIN/PPN/HAG at 1:1:1 molar ratio is submitted to 
LFP $\left(\lambda_{\text {exc }}=308 \mathrm{~nm}\right.$, air $)$, the decay trace monitored at $450 \mathrm{~nm}$ matches with that of the CIN/HAG system, with no contribution from ${ }^{3} \mathrm{PPN}^{*}$ in the kinetic decay. A similar situation is observed in the presence of BAG. Likewise, for the CIN/NAB/glycoprotein systems, the decay traces at $450 \mathrm{~nm}$ are identical to those of the CIN/glycoprotein mixtures, and ${ }^{3} \mathrm{NAB}^{*}$ does not contribute to the kinetic decay. These results clearly indicate an efficient energy transfer from ${ }^{3} \mathrm{PPN}^{*}$ or ${ }^{3} \mathrm{NAB}^{*}$ to $\mathrm{CIN}$ and reveal the occurrence of DDI between drugs that share a common protein binding site (see illustration of the concept in Figure 11). As the TTEnT process is completed within the duration of the laser pulse $(<20 \mathrm{~ns})$, deactivation of the excited triplet states is extremely fast, with a rate constant higher than $5 \times 10^{7} \mathrm{~s}^{-1}$. Such a high value is not compatible with the expectedly slow diffusion inside the protein binding sites and points to formation of pre-associated complexes between donor (PPN or NAB) and acceptor (CIN). This is confirmed by theoretical calculations, which combine atomistic and quantum-semiempirical methodologies (see optimised geometry in Figure 12).

\subsection{Aromatic ketones}

Ketoprofen (KPF) is a nonsteroidal antiinflammatory drug used for arthritis-related inflammatory pain. ${ }^{138}$ After LFP at $\lambda_{\text {exc }}=355 \mathrm{~nm}$ of KPF in the presence of BSA or HSA the transient absorption spectra exhibit two main bands at $320-330$ and $530 \mathrm{~nm}$, which decay in the microsecond time domain with two monoexponential terms. ${ }^{139,140}$ For BSA, in deaerated solutions, the short lifetimes (assigned to ${ }^{3} \mathrm{KPF}^{*}$ ) are $0.26 \mu$ s for $(S)-\mathrm{KPF}$ and $0.34 \mu$ s for $(R)-\mathrm{KPF}$. This is remarkable, since the triplet lifetime in neutral aqueous solution falls in the picosecond range. ${ }^{141,}{ }^{142}$ In HSA, ${ }^{3} \mathrm{KPF}^{*}$ is believed to abstract hydrogen from the protein matrix, generating ketyl radicals $\left(\lambda_{\max }=330\right.$ and 540 $\mathrm{nm})$. 
To study the influence of microheterogeneous media on the electronic configuration of the triplet excited state, 4,4-dimethoxybenzophenone (DMB) has been encapsulated in HSA. ${ }^{143}$ Thus, aqueous solutions containing DMB and HSA (molar ratio from 1:0 to $1: 5$ ) in neutral PBS buffer have been submitted to LFP. The DMB transient absorption spectrum obtained after excitation at $\lambda_{\mathrm{exc}}=355 \mathrm{~nm}$ in the presence of HSA is similar to that obtained in acetonitrile, but different from that recorded in PBS solution. The spectral shape modifications upon addition of HSA point to a reequilibration between $\pi \pi^{*}$ and $n \pi^{*}$ triplets within the lipophilic protein cavities. Moreover, HSA complexation leads to clear changes in the decay traces up to $1: 2.5$ molar ratios. The decay kinetics, monitored at $430 \mathrm{~nm}$ in air-equilibrated solutions, fit well with three lifetimes of $0.45,1.4$, and $14.4 \mu$ s. The shortest-living component is associated with the presence of free DMB in the bulk solution, previously determined in PBS. The other two longer lifetimes are correlated with the existence of two HSAbound species. Addition of oleic acid and ibuprofen as displacement probes confirms assignment of the 14.4 and $1.4 \mu$ s components to DMB within site I and site II, respectively.

Laser excitation $(355 \mathrm{~nm}$ ) of the flavonoid-derivative licochalcone A (LCA) in Ar saturated PBS leads to weak and broad transient absorption band in the 550-580 nm, region, which decays monoexponentially with a lifetime of $2.4 \mu \mathrm{s} .{ }^{56,57}$ In the presence of equimolar HSA the decay kinetics is biexponential, with lifetimes of 0.9 and $6.0 \mu \mathrm{s}$. This is explained as ${ }^{3} \mathrm{LCA}^{*}$ being present in the two sites of HSA involved in complexation. A similar behaviour is observed in BSA.

\subsection{Salicylic acid derivatives}

The molecular basis of photoallergy mediated by HTB has been investigated following the interaction between this drug metabolite and HSA by LFP $\left(\lambda_{\text {exc }}=308 \mathrm{~nm}\right) .{ }^{64}$ The 
results are consistent with complexation of HTB to site I of HSA. The HTB transient spectrum in PBS displays a maximum at $500 \mathrm{~nm}$, attributed to the excited triplet state, together with the solvated electron at $690 \mathrm{~nm}$. In the presence of an equimolar concentration of HSA (under air) only the T-T absorption is observed, with a triplet lifetime of $12 \mu \mathrm{s}$, which is considerably longer than in PBS $(0.6 \mu \mathrm{s})$. According to the kinetic data, HTB binding to HSA is nearly complete at 1:1 molar ratio, and only one of the two protein binding sites is occupied. For site assignment, oleic acid and ibuprofen have been employed to displace HTB; the data are consistent with preferential binding of HTB to site I.

\subsection{Heterobicyclic compounds}

Quenching of the triplet excited states of the antimalarial drug quinine (QIN) has been observed in BSA and attributed to the effect of Trp. By contrast, in the case of the analogous drug quinacrine (QIC), the triplet excited state is only slightly quenched by BSA, and no appreciable spectral changes are detected. ${ }^{144}$

Transient absorption measurements have been used to assess whether excitation $(355 \mathrm{~nm})$ of coumarin- or psoralen-HSA complexes results in any net photochemistry. ${ }^{83}$ At high HSA/substrate ratios the amount of uncomplexed substrate is minimised. For oxygen saturated 6,7-DMC (dimethoxycoumarin)/HSA in aqueous buffer, a transient at $500 \mathrm{~nm}$ is observed, decaying over a timescale of $5 \mu \mathrm{s}$; it can be assigned either to the triplet excited state in a site that is not accessible to oxygen or to a tryptophan-derived radical generated by trapping of the initial coumarin radical cation. For 5,7-DMC and 4'-amino-4,5',8-trimethylpsoralen (ATM) in HSA, similar transient species at $500 \mathrm{~nm}$ for oxygen-saturated solution and a stronger broader signal in the $500 \mathrm{~nm}$ region for nitrogen purged solutions are detected, but there is no evidence for radical cation formation. By contrast, laser excitation of 8-methoxypsoralen (8-MOP) does not give a 
$500 \mathrm{~nm}$ signal. These results can be explained by assuming that the triplet absorbs at shorter wavelength $(<400 \mathrm{~nm})$ or that the photoionisation efficiency for 8 -MOP is considerably lower than that for the methoxycoumarins.

Laser flash photolysis of the quinolone derivative nalidixic acid (NAL) at $355 \mathrm{~nm}$ in neutral medium, in the presence of HSA or BSA, evidences a significant shortening of the triplet lifetime $\left(\lambda_{\max }=630 \mathrm{~nm}\right)$, attributed to electron transfer reaction with the amino acid residues of the protein. ${ }^{88}$ Likewise, the triplet signal of NOR at $610 \mathrm{~nm}$ generated by LFP in the presence of BSA decays faster than in solution due to reaction with the matrix. ${ }^{91}$ However, independent work has found that the interaction of NOR and a series of related FLQs (ENO, CIP, OFL) with HSA or BSA are very weak $\left(\mathrm{K}_{\mathrm{B}}\right.$ in the range of $\left.10^{2}\right) .{ }^{90}$ The FLQ lifetimes and quantum yields do not appear to be affected by the presence of albumins, pointing to their predominant presence in the bulk solution.

\subsection{Tricyclic aromatics}

Nanosecond LFP $\left(\lambda_{\text {exc }}=308 \mathrm{~nm}, \mathrm{PBS} / \mathrm{Ar}\right)$ has been performed on solutions of $(R)$ - or (S)-CPF with HSA (1:1 molar ratio); ${ }^{94,} 145$ similar T-T absorption spectra are detected for both CPF stereoisomers (Figure 13A), but significant stereodifferentiation is observed in the kinetic traces (Figure 13B). The decay dynamics shows the presence of two components with different lifetimes that are correlated with complexation of CPF to the two high-affinity albumin binding sites; the two values determined for $(R)$-CPF $(8.9$ and $40 \mu \mathrm{s})$ are longer than those obtained for $(S)$-CPF $(2.3$ and $24 \mu \mathrm{s})$. The shorter lifetimes, for which stereodifferentiation is more important, are ascribed to ${ }^{3} \mathrm{CPF}^{*}$ in site I. This is attributed to electron-transfer quenching by the only Trp residue present in this site of the protein. The stereodifferentiation detected in the triplet decays correlates well with the relative reactivity in the photodehalogenation process (see Section 4). 
Stereodifferentiation is also observed in the covalent photobinding of CPF to HSA, the key process involved in the onset of the clinically reported photoallergy.

As stated above, ANA has been employed as a water-compatible anthracene derivative to investigate the photophysical behaviour of this chromophore upon binding to proteins. ${ }^{95}$ While LFP of ANA at $\lambda_{\text {exc }}=355 \mathrm{~nm}$ in PBS/air gives rise to several transient species (benzylic-type radical, radical anion, triplet excited state, radical cation and hydrated electron), in the presence of one equivalent of protein only the triplet excited state is detected (maximum at $420 \mathrm{~nm}$ ). The triplet lifetime lengthens considerably (up to 50-fold) in the protein media. The presence of two binding sites in albumins is associated with the kinetic evidence for two different triplet lifetimes; the major, longer-lived component under non-saturating conditions is assigned to site II, while the minor component corresponds to site I. By contrast, only one $\tau_{\mathrm{T}}$ value is found within glycoproteins, where only one binding site is available for ANA.

A parallel study has been performed on $(S)$ - and $(R)$-ANP as chiral reporters for their binding to proteins. ${ }^{96}$ As in the case of ANA, ANP shows a very complex transient absorption spectrum in aqueous solution (Figure 14A); however, for the ANP@protein complexes, only the band attributed to the lowest triplet excited state is observed (Figure 14B). Under aerobic conditions, the triplet lifetimes of both enantiomers, monitored at $420 \mathrm{~nm}$, are markedly longer in the protein media. In the case of albumins, two distinct intraprotein microenvironments are revealed by two different triplet lifetimes; their assignment is based on quenching by the Trp residue at site I of the albumins. Thus, the longer lifetime in the presence of albumins is ascribed to ANP located in site II, while the shorter one is safely assigned to ANP within the Trp containing site I. By contrast, only one lifetime is needed to fit the decays in the presence of glycoproteins, indicating only one binding site. As regards the accessibility 
of oxygen to ANP in protein media, the triplet quenching constants by oxygen are in the range $10^{7}-10^{8} \mathrm{M}^{-1} \mathrm{~s}^{-1}$, markedly lower than in solution and site-dependent (Figures $14 \mathrm{C}$, D).

Rose bengal (RBG) is a widely used singlet oxygen sensitiser. Association of this dye to HSA leads to a noticeable decrease in the rate of ${ }^{3} \mathrm{RBG}^{*}$ quenching by oxygen (one order of magnitude). ${ }^{146}$ This result implies that excited triplets are bound to high affinity sites that are relatively protected from oxygen coming from the external medium. This protection reflects a low solubility and/or mobility of $\mathrm{O}_{2}$ inside the protein and implies that the excited triplet remains incorporated to the protein and is not expelled to the surrounding solvent during its lifetime.

\subsection{Miscellaneous compounds}

When LFP of the antiarthritic and anticancer drug COL $\left(\lambda_{\text {exc }}=355 \mathrm{~nm}\right)$ is performed in aqueous media, in the presence or absence of HSA no transient species is detected. ${ }^{147}$ Selective irradiation of COL in aqueous medium at long wavelength (350 $\mathrm{nm}$ ) leads to photoisomerisation to $\beta$-lumicolchicine ( $\beta$-LCL) as major product, together with minor amounts of $\gamma$-LCL, irrespective of the presence or absence of protein. After LFP of irradiated COL/HSA and COL/BSA mixtures, long-lived $(>10 \mu \mathrm{s})$ transient species are detected, with absorption maxima at $c a .370$ and $600 \mathrm{~nm}$, assigned to the ${ }^{3}$ LCL*@albumin complexes. Interestingly, LFP of $\beta$ - and $\gamma$-LCL in aqueous solution in the absence of protein does not give rise to any detectable transient species. Laser excitation of colchiceine (CEI) in buffered aqueous medium does not generate any transient either, in agreement with the results obtained for COL and LCL. However, in the presence of HSA, transient absorption spectra very similar to those of ${ }^{3} \mathrm{COL}^{*}$ in acetonitrile are recorded. ${ }^{148}$ The LFP experiments confirm a very low binding affinity of COL to HSA $\left(\mathrm{K}_{\mathrm{B}}\right.$ lower than $\left.10^{3} \mathrm{M}^{-1}\right)$ compared to CEI $\left(\mathrm{K}_{\mathrm{B}}>10^{4} \mathrm{M}^{-1}\right)$. 
The halogenated squaraine dyes SQB and SQI have been submitted to laser flash photolysis $\left(\lambda_{\text {exc }}=532 \mathrm{~nm}\right)$ in the presence of HSA. ${ }^{116}$ The triplet lifetimes are much longer than to those determined in buffer, pointing to an efficient encapsulation of the dyes within HSA.

\section{Intraprotein photoreactivity}

The use of proteins as supramolecular systems to influence the course of organic photoreactions has attracted increasing interest over the last two decades. The welldefined 3D structure of serum albumins, with identification of the binding pockets, has been particularly useful to anticipate the capability of these proteins to interact with a large number of ligands. Specifically, the photoreactivity of encapsulated substrates can be modified by providing protection from attack by oxygen or other external reagents, by imposing conformational restrictions in the binding pockets, or by influencing the stereochemical outcome through the supply of a chiral source. In this context, special attention has been paid to asymmetric photochemistry or photochirogenesis as a new tool for the preparation of enantiomerically enriched compounds. A selected group of examples (Chart 1) demonstrating the potential of protein hosts to modify the course of organic photoreactions are presented below.

The first example of supramolecular photochirogenesis using a protein as supramolecular host is enrichment in the $(R)$-antipode after irradiation of racemic $1,1^{\prime}$ bi-2-naphthol (BNP). ${ }^{149-152}$ In the presence of BSA an enantiomeric excess (ee) of $99 \%$ is observed after a conversion yield of $77 \% .^{151}$ This high ee has been explained on the basis of different protein binding properties of the $(R)$ - and $(S)$-enantiomers. Interestingly, $(S)$-BNP@BSA exhibits a more intense UVA band than its $(R)$ counterpart, attributed to its presence as naphtholate. Hence, the reported ee has been

mainly associated with the higher absorption of $(S)$-BNP@BSA at the irradiation 
wavelength. In addition to the kinetic resolution arising from decomposition, photoinversion of $(S)$-BNP@BSA to $(R)$-BNP@BSA also contribute to the obtained results, albeit to a lesser extent. Interestingly, a species-dependent photobehaviour is observed, with HSA performing less efficiently (46\% ee, $65 \%$ conversion) than BSA, under the same conditions. ${ }^{150}$

Stereodifferentiation in the photolysis of drugs within protein matrix has received little attention with only two examples reported until now. ${ }^{94,139,145,151,153}$ Ketoprofen (KPF) exhibits a medium dependent photochemistry. ${ }^{46}$ In organic solvents, it presents the typical benzophenone photoreactivity, while in neutral aqueous medium an efficient photodecarboxylation takes place from the carboxylate anion. The latter process is triggered by intramolecular electron transfer from the carboxylate group to the excited carbonyl, yielding 3-ethylbenzophenone as main product. ${ }^{46}$ In serum albumins, photodecarboxylation is still the main pathway but it occurs with a considerably lower quantum yield than in water, ${ }^{139,153}$ and only a low (BSA) or insignificant (HSA) optical enrichment in $(S)$-KPF is observed upon photodestruction. ${ }^{151}$ In competition with photodecarboxylation, photobinding of KPF to the proteins has been reported. ${ }^{139,154,155}$ This is interesting from the photobiological point of view, as covalent photoadduct formation is in the origin of the clinically reported photoallergy.

Serum albumin-mediated stereodifferentiation has also been observed in the photochemistry of CPF. $^{94,145}$ By contrast with KPF, photodecarboxylation is in this case a minor reaction pathway, so the CPF chiral centre is conserved during the photoreaction. The prevailing photochemical process is cleavage of the $\mathrm{C}-\mathrm{Cl}$ bond that yields a dehalogenated photoproduct (PPF). ${ }^{94,145}$ As stated above (Section 3.6), the stereodifferentiation observed for triplet lifetimes correlates well with the photodegradation kinetics, which is faster for $(S)$-CPF@HSA. Irradiation of CPF alone 
in PBS leads to bleaching of the fluorescence band, due to polymerisation; by contrast, enhanced emission is observed for $(R)$ - and $(S)$-CPF@HSA. This is attributed to formation of PPF, whose emission quantum yield is 6 times higher than that of CPF and is $10 \mathrm{~nm}$ blue-shifted (Figure 15A). Accordingly, chiral HPLC analysis of the photolysates shows formation of $(S)$-PPF 1.5 times more efficient than that of $(R)$-PPF inside the protein (Figure 15B). In addition, photobinding to HSA occurs with efficiency somewhat higher for the $(R)$-isomer (Figure 15A, inset)..$^{94,145}$

In this context, it is important to underline that albumins have been extensively investigated as model systems for drug-induced photoallergy, an immunological response triggered by formation of a covalent photoadduct between a protein and a photosensitising drug. In addition to the abovementioned KPF and CPF, a number of drugs have demonstrated photobinding capability. ${ }^{156}$ In this context, a detailed study has been performed with HTB in the presence of proteins, to elucidate the mechanism involved in photoadduct formation. ${ }^{157}$ In addition to prove photobinding to BSA after sephadex filtration, it has been established that the $\varepsilon-\mathrm{NH}_{2}$ group of lysine is involved in the photoreaction. Accordingly, irradiation of HTB in the presence of poly-L-lysine also leads to photoaddition by nucleophilic attack of the free amino group to the trifluoromethyl moiety (Figure 16). ${ }^{64}$

The [4+4] photocyclodimerisation of the achiral ANC gives rise to four regioisomers (Figure 17), namely the anti- and syn-head-to-tail (HT), and the anti- and syn-head-to-head (HH). Among them, only syn-HT and anti-HH are chiral compounds.

The photodimerisation rate is retarded in the presence of BSA. $^{99}$ More interestingly, complexation of ANC with BSA affects the $\mathrm{HT} / \mathrm{HH}$ ratio. Indeed, in the absence of protein, the HT isomers are predominantly formed, whereas encapsulation within BSA inverts the regioselectivity and favours formation of the $\mathrm{HH}$ products. It has 
been proposed that $\mathrm{HH}$ dimerisation is more difficult in the bulk solution due to electrostatic repulsion between the negatively charged carboxylate moieties; however, within BSA this is counterbalanced by interactions between the ANC molecules and the cationic amino acid residues, leading to enhanced $\mathrm{HH}$ dimerisation. ${ }^{99}$ Furthermore, BSA provides a chiral source that has a marked influence on the stereoselectivity of syn-HT and anti-HH dimers formation from achirals ANC, which have been obtained with moderate enantiomeric excess. ${ }^{99}, 100$ In this context, the photochirogenic properties of the different binding sites have been investigated using nitromethane as quencher of the ANC singlet excited state. ${ }^{100}$ The presence of nitromethane results in an increase of the ee of syn-HT, with the concomitant decrease of that of anti-HH. These data combined with the fluorescence results (see Section 2.6), suggest that the stereoselectivity is sitedependent. A similar study has been performed with HSA as host. ${ }^{98,101,158}$ In this case, the protein-mediated photocyclodimerisation ensues with enhanced HT dimers formation. Moreover, remarkably higher ee are obtained up to 79 and $88 \%$ for syn-HT and anti-HH, respectively. It is noteworthy, that the same enantiomer of anti-HH is preferentially formed in both albumins, while the antipodes are favoured in the case of syn-HT. ${ }^{98-101,158}$

To expand the range of biomolecular hosts, the [4+4] photocyclodimerisation of ANC has been investigated in the presence of a molecular chaperone protein, the archaeal prefoldin from Pyrococcus horikoshii OT3 (PFD). ${ }^{159}$ In the presence of PFD, similar conversions are obtained as in the bulk solution. In addition, a moderate decrease of the HT-dimers is noticed and only a marginal ee is achieved for the syn-HT and anti-HH dimers. These results point to a higher mobility of ANC in the PFD binding sites than in those of serum albumins. Nonetheless, protein encapsulation still 
allows alignment of two ANC molecules leading to $\mathrm{HH}$ dimers, which are sterically and electrostatically disfavoured in solution.

Photodimerisation of anthracene inside albumins requires the use of high ligand to protein ratios. However, under non-saturating conditions it is unlikely that two anthracene units are found within the same binding site, so this process is prevented and other reaction channels are opened. ${ }^{95,} 96$ In this context, photooxidation of ANA has been examined using different transport proteins such as HSA, BSA, HAG and BAG at 1:1 molar ratio. ${ }^{95}$ Irradiation of aerated PBS solutions of ANA yields anthraquinone as product. This photooxidation process occurs through a triplet-triplet energy transfer from ${ }^{3}$ ANA* to molecular oxygen, generating singlet oxygen $\left({ }^{1} \mathrm{O}_{2}\right)$. This species reacts with ANA by a formal [4+2] cycloaddition to the central anthracene ring; rearrangement of the resulting endoperoxide followed by cleavage of the 9-substituent leads to anthraquinone. Under these conditions, photooxidation is markedly slower than in PBS solution; the most remarkable result is found for serum albumins, where the reaction rate constant is one order of magnitude lower. This indicates that the protein cavities provide an important protection towards photooxidation, which is attributed to a slower diffusion of oxygen inside the protein.

A dramatic stereodifferentiation in the photooxidation process has been found in the related $(S)$ - and $(R)$-ANP. ${ }^{96}$ For instance, in the presence of HSA the reaction rate constant is higher for the $(S)$-enantiomer, leading to a kinetic resolution with enhancement of the less reactive (R)-ANP (ee of $c a .34 \%$ after 120 min of irradiation). From a mechanistic point of view, involvement of singlet oxygen in the photooxidation is confirmed by the remarkable acceleration of reaction rates in $\mathrm{D}_{2} \mathrm{O}$, in agreement with the longer lifetime of ${ }^{1} \mathrm{O}_{2}$ in this medium. Overall, the retarded photooxidation within the protein binding sites is in good agreement with the lower rate constants obtained for 
quenching of encapsulated ${ }^{3}$ ANP* by oxygen (see Section 3.6). Further experiments using selectively excited photosensitisers that are not present in the same microenvironments as ANP demonstrate that photooxidation is compartmentalised.

Unimolecular processes do not require diffusion of the reactants, so they appear particularly suitable to evaluate the influence of intraprotein microenvironments on photoreactivity. With this aim, the Norrish type II fragmentation of 1,1-(4-tertbutylbenzoyl)-(4'-methoxybenzoyl)butane, also known as propylavobenzone (PAB), gives rise to clean generation of avobenzone (ABZ). ${ }^{160}$ Since $\mathrm{ABZ}$ is a widely used UVA filter in sunscreens, PAB can be considered as a pro-filter. Formation of ABZ can be monitored by steady-state UV-Vis spectrophotometry, through the appearance of an absorption band with maximum at $355 \mathrm{~nm}$. In the LFP experiments, the transient absorption band corresponding to ${ }^{3} \mathrm{PAB}^{*}$ at $\lambda_{\max }=400 \mathrm{~nm}$ is initially observed (Figure 18); formation of $\mathrm{ABZ}$ from this precursor is detected by the appearance of the abovementioned maximum at $355 \mathrm{~nm}$, which does not decay in the microsecond timescale (Figure 18). The reaction kinetics is slower in the presence of HSA, where the quantum yield is 2.8 times lower $\left(\phi_{\mathrm{R}}=1.4 \times 10^{-2}\right)$ than in acetonitrile. A satisfactory correlation is found between the decreased PAB photoreactivity and the increased ${ }^{3} \mathrm{PAB}^{*}$ lifetime when encapsulated in the protein. This suggests that the conformation required for intramolecular abstraction of the $\gamma$-hydrogen by the excited carbonyl is disfavoured within the confined HSA microenvironment.

The classical photo-Fries rearrangement has also been used as a probe reaction to evaluate the influence of serum albumins of different species (HSA, BSA and rabbit serum albumin, RSA) as microheterogeneous media. ${ }^{161}$ In this context, 4-methoxy-1naphthyl hydrogen glutarate (MNG) and the analogous acetate (MNA) are chosen because of their selective interaction with albumins in site II and site I, respectively. Site 
assignment is established by fluorescence displacement experiments using dansylamide and dansylglycine as specific probes. The photo-Fries rearrangement of MNG and MNA proceeds via homolytic cleavage of the naphthyloxy-carbonyl bond from the singlet excited state and leads to formation of ortho-acyl naphthols after in cage recombination of the radical pairs. The presence of HSA significantly affects the quantum yield of photoproduct formation, which decreases in the case of MNG from $c a$. 0.16 in PBS down to $c a$. 0.06 within the protein. Moreover, the photoproduct is formed 2.3 times more efficiently for MNA than for MNG, which supports a site-dependent reactivity of the intraprotein photorearrangement. Concerning the influence of the albumin species, the quantum yields of photoreaction within BSA are enhanced but the difference between the two binding sites is less pronounced. Interestingly, the same result has been determined for both substrates within RSA, which is compatible with the existence of only one common binding site in this protein.

Oxidative photocyclisation of $N$-methyldiphenylamine (DPA) is an interesting reaction that occurs through a multistep pathway involving two consecutive triplet excited states (Figure 19A). ${ }^{162}$ Hence, the short-lived triplet excited state $\left({ }^{3} \mathrm{DPA} *\right)$, generated after excitation and intersystem crossing undergoes an adiabatic ring closure, leading to the $N$-methyl-4a,4b-dihydrocarbazole triplet excited state $\left({ }^{3} \mathrm{DHC} *\right.$ ). This species crosses to its ground state (DHC) and undergoes dehydrogenation in the presence of molecular oxygen, giving rise to $N$-methylcarbazole (MCZ) as final product. By contrast, under anaerobic conditions DHC ring-opens back to the starting DPA. ${ }^{162}$ Interestingly, oxygen plays a dual role in this photoreaction. On the one hand, it quenches the amine triplet excited state disfavouring $\mathrm{MCZ}$ formation; on the other hand, it is required as a reagent for the final DHC oxidation. The efficiency of DPA photocyclisation is maximised within the albumin binding sites. The photocyclisation 
quantum yields are markedly enhanced in the presence of serum albumins (Figure 19B). It is noteworthy that the highest efficiency is obtained for oxygen-saturated solutions of DPA@BSA, which is very close to the upper limit imposed by the intersystem crossing quantum yield of DPA (0.8-0.9) (Figure 19A). Detailed information on the involved processes is obtained by LFP monitoring the $610 \mathrm{~nm}$ traces of ground state DHC. In aerated PBS, the decay follows a first order exponential law with a lifetime of $15 \mu \mathrm{s}$. Encapsulation of DPA within albumins is associated with the presence of two lifetime components (15 and $451 \mu$ s for HSA, or 15 and $384 \mu$ s for BSA). These data, together with site displacement experiments, show that at DPA/serum albumin 1:1 molar ratio, ca. $90 \%$ of the substrate is complexed within site I of the protein. The observed behaviour is associated with the slow intraprotein diffusion of oxygen that leads to inefficient quenching of the short-lived ${ }^{3}$ DPA*@serum albumin. Finally, the $610 \mathrm{~nm}$ intermediate is quenched by oxygen with a rate constant in the range of $10^{5} \mathrm{M}^{-1} \mathrm{~s}^{-1}, \mathrm{ca} .2$ orders of magnitude lower than oxygen diffusion within protein binding site I. This explains why the final dehydrogenation of $\mathrm{DHC}$ to $\mathrm{MCZ}$ is not affected by complexation.

Finally, the enantioselective $6 \pi$ electrocyclisation of a family of photochromic bis-thienylethenes (BTE), namely 1,2-bis(2,5-dimethyl-3thienyl)hexafluorocyclopentene (BTE-1), 1,2-bis(2-hydroxymethyl-5-methyl-3thienyl)hexafluorocyclopentene (BTE-2) and 1,2-bis(5-hydroxymethyl-2-methyl-3thienyl)hexafluorocyclopentene (BTE-3) has also been carried out inside HSA. ${ }^{163}$ For the three compounds, the ring closing reaction results in formation of two enantiomers. In general, the highest conversion ratio and ee have been obtained at high HSA/substrate molar ratios. ${ }^{163}$ 


\section{Summary and Outlook}

Binding to proteins plays an important role in the pharmacological activity, biodistribution and metabolism of drugs. Drug@ protein supramolecular assemblies can be advantageously investigated by photophysical methods (noteworthy steady-state and time-resolved fluorescence, as well as transient absorption spectroscopy) when the drugs of interest contain a photoactive chromophore. This approach is particularly useful when such chromophore can be selectively excited at long wavelengths, where the aromatic amino acids of the proteins do not absorb. Since singlet and triplet excited states exhibit strongly medium-dependent properties, they can be used as reporters to probe the microenvironments defined by protein binding sites. Specifically, the fluorescence quantum yields and lifetimes provide key data to determine the stoichiometry of the complex, the binding constant, the lipophilicity of binding sites and the relative degrees of occupancy of the different compartments. In addition, transient absorption spectroscopy leads to formation of encapsulated triplet excited states, a process which is strongly favoured over generation of ionic species (i. e. radical ions). The resulting ${ }^{3} \mathrm{drug}^{*} @$ protein entities display photophysical properties that can be successfully used to gather information on interaction strength, conformational restrictions, protection from attack by external agents, etc. Interestingly, the triplet lifetimes of protein-complexed drugs are remarkably long (even under aerobic conditions), providing a broad dynamic range for identification of distinct triplet populations or for chiral discrimination.

The use of proteins as supramolecular hosts modifies the photoreactivity of encapsulated substrates by controlling the traffic of reactants between the bulk solution and the intraprotein microenvironments, by imposing conformational restrictions in the binding pockets, by making use of the amino acid residues as active centers, or by 
supplying a chiral source that influences the stereochemical outcome. As a proof of the concept, the potential of proteins as hosts capable to modify the course of organic photoreactions has been demonstrated in selected examples that include decarboxylation, dehalogenation, dimerisation, rearrangement or cyclisation, among others.

On the basis of the existing knowledge, there is clearly room for future work on photoactivedrug@protein assemblies. Thus, the use of triplet excited states as reporters can be further developed to exploit the specific advantages of these species, in particular the broader dynamic range, the possibility to investigate relatively slow processes (for instance, relocation), and the unambiguous information provided on direct interactions that need a close contact between the involved partners (collisions), free from interferences associated with processes operating at longer distances (i. e., FRET). As regards the use of protein binding sites as nanoreactors for photochemical processes, the next step forward seems the design of photocatalytic systems, which would be possible when the binding constants of the reactants are substantially higher than those of the photoproducts. In addition, the reaction in the bulk solution should be minimised, for instance by achieving selective excitation of the complexes. Ideally, the protein binding sites should play an active role, working not only as constraining cavities but also contributing to the catalytic process with participation of the active centers provided by the amino acid residues.

\section{Acknowledgements}

Financial support from the Spanish Government (CTQ2010-14882, JCI-2011-09926, RyC-2007-00476), from the EU (PCIG12-GA-2012-334257), from the Universitat Politècnica de València (SP20120757) and from the Consellería de Educació, Cultura i Esport (PROMETEOII/2013/005, GV/2013/051) is gratefully acknowledged. 


\section{References}

1. U. Kragh-Hansen, V. T. G. Chuang and M. Otagiri, Biol. Pharm. Bull., 2002, 25, 695704.

2. T. Peters, All About Albumins: Biochemistry Genetics and Medical Applications, Academic Press, San Diego, 1995.

3. S. Sugio, A. Kashima, S. Mochizuki, M. Noda and K. Kobayashi, Protein Eng., 1999, 12, 439-446.

4. T. Wybranowski, M. Cyrankiewicz, B. Ziomkowska and S. Kruszewski, Biosystems, 2008, 94, 258-262.

5. D. C. Carter and J. X. Ho, Advances in Protein Chemistry, Academic Press, New York, 1994, vol. 45, pp. 152-203.

6. K. Vuignier, J. Schappler, J.-L. Veuthey, P.-A. Carrupt and S. Martel, Anal. Bioanal. Chem., 2010, 398, 53-66.

7. X. M. He and D. C. Carter, Nature, 1992, 358, 209-215.

8. T. C. Kwong, Clin. Chim. Acta, 1985, 151, 193-216.

9. B. X. Li, Z. J. Zhang and L. X. Zhao, Anal. Chim. Acta, 2002, 468, 65-70.

10. C. K. Svensson, M. N. Woodruff, J. G. Baxter and D. Lalka, Clin. Pharmacokinet., 1986, 11, 450-469.

11. G. Sudlow, D. J. Birkett and D. N. Wade, Mol. Pharmacol., 1976, 12, 1052-1061.

12. K. Schmid, H. Kaufman, S. Isemura, F. Bauer, J. Emura, T. Motoyama, M. Ishiguro and S. Nanno, Biochemistry, 1973, 12, 2711-2724.

13. V. Z. Kopitar and H. Weisenberger, Arzneim.-Forsch. (Drug Res.), 1971, 21, 859-862.

14. M. L. Friedman, J. R. Wermeling and H. B. Halsall, J. Biochem., 1986, 236, 149-153.

15. J. P. Aubert and M. H. Loucheaux-Lefebvre, Arch. Biochem. Biophys., 1976, 175, 400409.

16. V. Kopecky, R. Ettrich, K. Hofbauerova and V. Baumruk, Biochem. Biophys. Res. Commun., 2003, 300, 41-46.

17. A. Rojo-Dominguez and A. Hernandez-Arana, Protein Seq. Data Anal., 1993, 5, 349355.

18. T. Hochepied, F. G. Berger, H. Baumann and C. Libert, Cytokine Growth Factor Rev., $2003,14,25-34$.

19. K. Schmid, J. Am. Chem. Soc., 1953, 75, 60-68.

20. K. Schmid, R. B. Nimberg, A. Kimura, H. Yamaguchi and J. P. Binette, Biochim. Biophys. Acta, 1977, 492, 291-302.

21. K. Matsumoto, K. Sukimoto, K. Nishi, T. Maruyama, A. Suenaga and M. Otagiri, Drug Metab. Pharmacokinet., 2002, 17, 300-306.

22. H. Aki and M. Yamamoto, J. Pharm. Pharmacol., 1989, 41, 674-679. 
23. J. Barré, J. M. Chamouard, G. Houin and J. P. Tillement, Clin. Chem., 1985, 31, 60-64.

24. W. F. Bowers, S. Fulton and J. Thompson, Clin. Pharmacokinet., 1984, 9, 49-60.

25. Y. H. Chu, L. Z. Avila, H. A. Biebuyck and G. M. Whitesides, J. Med. Chem., 1992, 35, 2915-2917.

26. J. Flarakos, K. L. Morand and P. Vouros, Anal. Chem. , 2005, 77, 1345-1353.

27. A. Frostell-Karlsson, A. Remaeus, H. Roos, K. Andersson, P. Borg, M. Hämäläinen and R. Karlsson, J. Med. Chem., 2000, 43, 1986-1992.

28. Z. Jia, T. Ramstad and M. Zhong, J. Pharm. Biomed. Anal., 2002, 30, 405-413.

29. L. H. Lucas, K. E. Price and C. K. Larive, J. Am. Chem. Soc., 2004, 126, 14258-14266.

30. H. H. Parikh, K. McElwaine, V. Balasubramanian, W. Leung, D. Won, M. E. Morris and M. Ramanathan, Pharm. Res., 2000, 17, 632-637.

31. A. Shibukawa, Y. Kuroda and T. Nakagawa, J. Pharm. Biomed. Anal., 1999, 18, $1047-$ 1055 .

32. Q. Zhang, Y. Huang, R. Zhao, G. Liu and Y. Chen, Biosens. Bioelectron., 2008, 24, 4854.

33. R. Zini, D. Morin, P. Jouenne and J. P. Tillement, Life Sci., 1988, 43, 2103-2115.

34. A. Buranaprapuk, C. V. Kumar, S. Jockusch and N. J. Turro, Tetrahedron, 2000, 56, 7019-7025.

35. K. K. Chin, C. C. Trevithick-Sutton, J. McCallum, S. Jockusch, N. J. Turro, J. C. Scaiano, C. S. Foote and M. A. Garcia-Garibay, J. Am. Chem. Soc., 2008, 130, 69126913.

36. N. Deo, S. Jockusch, N. J. Turro and P. Somasundaran, Langmuir, 2003, 19, 50835088 .

37. C. V. Kumar, A. Buranaprapuk, H. C. Sze, S. Jockusch and N. J. Turro, Proc. Natl. Acad. Sci. U. S. A., 2002, 99, 5810-5815.

38. N. J. Turro and X.-G. Lei, Langmuir, 1995, 11, 2525-2533.

39. C. J. Yang, S. Jockusch, M. Vicens, N. J. Turro and W. Tan, Proc. Natl. Acad. Sci. U. S. A., 2005, 102, 17278-17283.

40. W. F. Kean, E. J. Antal, E. M. Grace, H. Cauvier, J. Rischke and W. W. Buchanan, J. Clin. Pharmacol., 1992, 32, 41-48.

41. A. M. Evans, J. Clin. Pharmacol., 1996, 36, 7S-15S.

42. I. Vaya, P. Bonancia, M. C. Jimenez, D. Markovitsi, T. Gustavsson and M. A. Miranda, Phys. Chem. Chem. Phys., 2013, 15, 4727-4734.

43. M. C. Jiménez, M. A. Miranda, R. Tormos, I. Vayá, Photochem. Photobiol. Sci., 2004, 3, 1038-1041.

44. W. P. Bartok, J. Lucchesi and N. S. Snider, J. Am. Chem. Soc. , 1962, 84, 1842-1844. 
45. P. Bonancía, I. Vayá, M. C. Jiménez and M. A. Miranda, J. Phys. Chem. B, 2012, 116, 14839-14843.

46. F. Bosca, M. L. Marin and M. A. Miranda, Photochem. Photobiol., 2001, 74, 637-655.

47. I. Vayá, R. Pérez-Ruiz, V. Lhiaubet-Vallet, M. C. Jiménez and M. A. Miranda, Chem. Phys. Lett., 2010, 486, 147-153.

48. M. González-Béjar, E. Alarcón, H. Poblete, J. C. Scaiano and J. Pérez-Prieto, Biomacromolecules, 2010, 11, 2255-2260.

49. A. E. Kruse, U. Eisenberg, F. J. Frey and M. G. Mohaupt, Nephrol. Dial. Transplant., 2005, 20, 1311-1314.

50. G. N. Kumar, C. Sproul, L. Poppe, S. Turner, M. Gohdes, H. Ghoborah, D. Padhi and L. Roskos, Drug Metab. Dispos., 2004, 32, 1491-1500.

51. E. D. Szmuilowicz and R. D. Utiger, Nat. Rev. Endocrinol., 2006, 2, 291-296.

52. N. Nagano, Pharmacol. Therapeut., 2006, 109, 339-365.

53. E. Nuin, I. Andreu, M. J. Torres, M. C. Jiménez and M. A. Miranda, J. Phys. Chem. B, 2011, 115, 1158-1164.

54. J. A. Organero, C. Martin, B. Cohen and A. Douhal, Langmuir, 2008, 24, 10352-10357.

55. Z. Nowakowska, Eur. J. Med. Chem., 2007, 42, 125-137.

56. S. Monti, I. Manet, F. Manoli and G. Marconi, Phys. Chem. Chem. Phys., 2008, 10, 6597-6606.

57. S. Monti, I. Manet, F. Manoli, S. Ottani and G. Marconi, Photochem. Photobiol. Sci., 2009, 8, 805-813.

58. J. R. Vane, Nature, 1971, 231, 232-235.

59. J. B. Smith and A. L. Willis, Nature, 1971, 231, 235-237.

60. P. E. Grimes, Dermatol. Surg., 1999, 25, 18-22.

61. P. A. Mackowiak, Clin. Infect. Dis., 2000, 31, 154-156.

62. W. E. Roberts, Dermatol. Ther., 2004, 17, 196-205.

63. G. L. Messa, M. Franchi, A. Auteri and T. Diperri, Int. J. Clin. Pharmacol. Res., 1993, 13, 263-273.

64. S. Montanaro, V. Lhiaubet-Vallet, M. C. Jiménez, M. Blanca and M. A. Miranda, ChemMedChem, 2009, 4, 1196-1202.

65. M. Lukeman and P. Wan, J. Am. Chem. Soc., 2003, 125, 1164-1165.

66. J. Keck, H. E. A. Kramer, H. Port, T. Hirsch, P. Fischer and G. Rytz, J. Phys. Chem. B, 1996, 100, 14468-14475.

67. B. K. Paul and N. Guchhait, J. Phys. Chem. B, 2011, 115, 10322-10334.

68. B. K. Paul and N. Guchhait, J. Phys. Chem. B, 2011, 115, 11938-11949.

69. B. Bhattacharya, S. Nakka, L. Guruprasad and A. Samanta, J. Phys. Chem. B, 2009, 113, 2143-2150. 
70. B. K. Paul, A. Samanta and N. Guchhait, Photochem. Photobiol. Sci., 2010, 9, 67-77.

71. B. K. Paul, A. Samanta and N. Guchhait, J. Mol. Struct., 2010, 977, 78-89.

72. B. K. Paul, D. Ray and N. Guchhait, Phys. Chem. Chem. Phys., 2012, 14, 8892-8902.

73. D. Ray, B. K. Paul and N. Guchhait, Phys. Chem. Chem. Phys., 2012, 14, 12182-12192.

74. J. R. Lakowicz, Principles of Fluorescence Spectroscopy, 3rd edn., Plenum Press, New York, 2006.

75. H. A. Benesi and J. H. Hildebrand, J. Am. Chem. Soc., 1949, 71, 2703-2707.

76. M. Haimsohm, R. Beery, A. Karasik, H. Kaneti and A. Geiger, Endocrinology, 2002, 143, 837-845.

77. M. Bardhan, T. Misra and T. Ganguly, J. Photochem. Photobiol. B, 2012, 106, 113-119.

78. M. Bardhan, J. Chowdhury and T. Ganguly, J. Photochem. Photobiol. B, 2011, 102, 1119.

79. J. Liu, J. Tian, X. Tian, Z. Hu and X. Chen, Biorg. Med. Chem., 2004, 12, 469-474.

80. Y. Li, W. He, Y. Dong, F. Sheng and Z. Hu, Biorg. Med. Chem., 2006, 14, 1431-1436.

81. M. El-Kemary, M. Gil and A. Douhal, J. Med. Chem., 2007, 50, 2896-2902.

82. E. Gonzalez, Dermatol. Clin., 1995, 13, 851-866.

83. L. Chen, O. Rinco, J. Popov, N. Vuong and L. J. Johnston, Photochem. Photobiol., 2006, 82, 31-37.

84. R. S. Ray, N. Agrawal, R. B. Misra, M. Farooq and R. K. Hans, Drug Chem. Toxicol., 2006, 29, 25-38.

85. R. Stahlmann and H. Lode, Drugs, 1999, 58, 37-42.

86. N. Wagai and K. Tawara, Arch. Toxicol., 1991, 65, 495-499.

87. T. Izumi and T. Kitagawa, Chem. Pharm. Bull., 1989, 37, 742-745.

88. S. Monti, I. Manet, F. Manoli, M. L. Capobianco and G. Marconi, J. Phys. Chem. B, 2008, 112, 5742-5754.

89. J. M. Domagala, L. D. Hanna, C. L. Heifetz, M. P. Hutt, T. F. Mich, J. P. Sanchez and M. Solomon, J. Med. Chem., 1986, 29, 394-404.

90. F. Bosca, J. Phys. Chem. B, 2012, 116, 3504-3511.

91. F. Dall'Acqua, G. Viola, D. Vedaldi, G. G. Aloisi, F. Elisei, L. Latterini and R. Passeri, ARKIVOC, 2007, 8, 231-244.

92. H. W. Sun and P. He, Chromatographia, 2008, 68, 969-975.

93. G. Zlotos, M. Oehlmann, P. Nickel and U. Holzgrabe, J. Pharm. Biomed., 1998, 18, 847-858.

94. V. Lhiaubet-Vallet, F. Boscá and M. A. Miranda, J. Phys. Chem. B, 2007, 111, 423431.

95. R. Alonso, M. Yamaji, M. C. Jimenez and M. A. Miranda, J. Phys. Chem. B, 2010, 114, 11363-11369. 
96. R. Alonso, M. C. Jimenez and M. A. Miranda, Org. Lett., 2011, 13, 3860-3863.

97. D. Fuentealba, H. Kato, M. Nishijima, G. Fukuhara, T. Mori, Y. Inoue and C. Bohne, J. Am. Chem. Soc., 2013, 135, 203-209.

98. M. Nishijima, T. Wada, T. Mori, T. C. S. Pace, C. Bohne and Y. Inoue, J. Am. Chem. Soc., 2007, 129, 3478-3479.

99. T. Wada, M. Nishijima, T. Fujisawa, N. Sugahara, T. Mori, A. Nakamura and Y. Inoue, J. Am. Chem. Soc., 2003, 125, 7492-7493.

100. M. Nishijima, T. C. S. Pace, A. Nakamura, T. Mori, T. Wada, C. Bohne and Y. Inoue, J. Org. Chem., 2007, 72, 2707-2717.

101. T. C. S. Pace, M. Nishijima, T. Wada, Y. Inoue and C. Bohne, J. Phys. Chem. B, 2009, 113, 10445-10453.

102. H. Satonaka, K. Kusuzaki, T. Matsubara, K. Shintani, T. Wakabayashi, T. Nakamura, A. Matsumine and A. Uchida, Anticancer Res., 2007, 27, 3339-3344.

103. B. Chakraborty, A. S. Roy, S. Dasgupta and S. Basu, J. Phys. Chem. A, 2010, 114, 13313-13325.

104. A. Sanchez Coronilla, C. Carmona, M. A. Muñoz and M. Balon, J. Fluoresc., 2009, 19, 1025-1035.

105. D. E. J. G. J. Dolmans, D. Fukumura and R. K. Jain, Nat. Rev. Cancer, 2003, 3, 380387.

106. A. Chakrabarty, A. Mallick, B. Haldar, P. Das and N. Chattopadhyay, Biomacromolecules, 2007, 8, 920-927.

107. B. K. Paul and N. Guchhait, J. Phys. Chem. B, 2011, 115, 10322-10334.

108. F. T. Vert, I. Z. Sanchez and A. O. Torrent, J. Photochem., 1983, 23, 355-368.

109. M. G. Korman, A. F. Hofmann and W. Summersk, N. Engl. J. Med., 1974, 290, 13991402 .

110. J. Rohacova, G. Sastre, M. L. Marin and M. A. Miranda, J. Phys. Chem. B, 2011, 115, 10518-10524.

111. M. Mukherjee, P. S. Sardar, S. K. Ghorai, S. K. Samanta, A. S. Roy, S. Dasgupta and S. Ghosh, J. Photochem. Photobiol. B, 2012, 115, 93-104.

112. M. Mukherjee, P. S. Sardar, S. K. Ghorai, S. K. Samanta, A. S. Roy, S. Dasgupta and S. Ghosh, PLoS One, 2013, 8, e60940.

113. K. Y. Law, Chem. Rev., 1993, 93, 487-505.

114. H. S. Hewage and E. V. Anslyn, J. Am. Chem. Soc., 2009, 131, 13099-13106.

115. V. S. Jisha, K. T. Arun, M. Hariharan and D. Ramaiah, J. Am. Chem. Soc., 2006, 128, 6024-6025.

116. V. S. Jisha, K. T. Arun, M. Hariharan and D. Ramaiah, J. Phys. Chem. B, 2010, 114, 5912-5919. 
117. C. Antoniades, D. Tousoulis, N. Koumallos, K. Marinou and C. Stefanadis, Pharmacol. Ther. , 2007, 114, 184-197.

118. B. Cohen, J. A. Organero, L. Santos, L. Rodriguez Padial and A. Douhal, J. Phys. Chem. B, 2010, 114, 14787-14795.

119. D. A. Phillips, C. M. Joseph, G.-P. Yang, E. Martinez-Romero, J. R. Sanborn and H. Volpin, Proc. Natl. Acad. Sci. U. S. A., 1999, 96, 12275-12280.

120. M. Gil, Y. Wang and A. Douhal, J. Photochem. Photobiol. A, 2012, 234, 146-155.

121. M. Marchena, M. Gil, C. Martin, J. A. Organero, F. Sanchez and A. Douhal, J. Phys. Chem. B, 2011, 115, 2424-2435.

122. R. Tormos and F. Bosca, RSC Adv., 2013, 3, 12031-12034.

123. I. Vayá, C. J. Bueno, M. C. Jiménez and M. A. Miranda, ChemMedChem, 2006, 1, 1015-1020.

124. L. Deschamps-Labat, F. Péhourcq, M. Jagou and B. Bannwarth, J. Pharm. Biomed. Anal., 1997, 16, 223-229.

125. T. Itoh, Y. Saura, Y. Tsuda and H. Yamada, Chirality, 1997, 9, 643-649.

126. M. C. Jiménez, M. A. Miranda and I. Vayá, J. Am. Chem. Soc., 2005, 127, 1013410135 .

127. I. Vaya, M. C. Jimenez and M. A. Miranda, J. Phys. Chem. B, 2008, 112, 2694-2699.

128. M. H. Rahman, K. Yamasaki, Y.-H. Shin, C. C. Lin and M. Otagiri, Biol. Pharm. Bull., 1993, 16, 1169-1174.

129. K. J. Fehske, K. J. Müller, U. Schläfer and U. Wollert, Prog. Drug Protein Binding, 1981, 5-15.

130. R. Pérez-Ruiz, C. J. Bueno, M. C. Jiménez and M. A. Miranda, J. Phys. Chem. Lett., 2010, 1, 829-833.

131. R. K. Verbeeck, J. L. Blackburn and G. R. Loewen, Clin. Pharmacokinet., 1983, 8, $297-$ 331.

132. C. J. Bueno, M. C. Jiménez and M. A. Miranda, J. Phys. Chem. B, 2009, 113, 68616865 .

133. I. Vayá, C. J. Bueno, M. C. Jiménez and M. A. Miranda, Chem. Eur. J., 2008, 14, 11284-11287.

134. S. Sortino, J. C. Scaiano and S. Giuffrida, New J. Chem., 1999, 23, 1159-1162.

135. R. 1. Pérez-Ruiz, R. Alonso, E. Nuin, I. Andreu, M. C. Jiménez and M. A. Miranda, J. Phys. Chem. B, 2011, 115, 4460-4468.

136. L. J. Martínez and J. C. Scaiano, Photochem. Photobiol., 1998, 68, 646-651.

137. E. Nuin, M. C. Jiménez, G. Sastre, I. Andreu and M. A. Miranda, J. Phys. Chem. Lett., 2013, 4, 1603-1607.

138. T. G. Kantor, Pharmacotherapy, 1986, 6, 93-103. 
139. S. Monti, I. Manet, F. Manoli, R. Morrone, G. Nicolosi and S. Sortino, Photochem. Photobiol., 2006, 82, 13-19.

140. S. Monti, I. Manet, F. Manoli and S. Sortino, Photochem. Photobiol. Sci., 2007, 6, 462470 .

141. M. D. Li, J. Ma, T. Su, M. Liu, L. Yu and D. L. Phillips, J. Phys. Chem. B, 2012, 116, 5885-5887.

142. S. Monti, S. Sortino, G. De Guidi and G. Marconi, J. Chem. Soc., Faraday Trans., 1997, 93, 2269-2275.

143. D. Jornet, R. Tormos and M. A. Miranda, J. Phys. Chem. B, 2011, 115, 10768-10774.

144. G. G. Aloisi, A. Barbafina, M. Canton, F. Dall'Acqua, F. Elisei, L. Facciolo, L. Latterini and G. Viola, Photochem. Photobiol., 2004, 79, 248-258.

145. V. Lhiaubet-Vallet, Z. Sarabia, F. Boscá and M. A. Miranda, J. Am. Chem. Soc., 2004, 126, 9538-9539.

146. E. Alarcon, A. M. Edwards, A. Aspee, C. D. Borsarelli and E. A. Lissi, Photochem. Photobiol. Sci., 2009, 8, 933-943.

147. P. Bartovsky, R. Tormos and M. A. Miranda, Chem. Phys. Lett., 2009, 480, 305-308.

148. F. Bosca and R. Tormos, J. Phys. Chem. B 2013, 117, 7528-7534.

149. N. Levi-Minzi and M. Zandomeneghi, J. Am. Chem. Soc., 1992, 114, 9300-9304.

150. M. Nishijima, J.-W. Chang, C. Yang, G. Fukuhara, T. Mori and Y. Inoue, Res. Chem. Intermed., 2013, 39, 371-383.

151. A. Ouchi, G. Zandomeneghi and M. Zandomeneghi, Chirality, 2002, 14, 1-11.

152. M. Zandomeneghi, J. Am. Chem. Soc., 1991, 113, 7774-7775.

153. C. Festa, N. Levi-Minzi and M. Zandomeneghi, Gazz. Chim. Ital., 1996, 126, 599-603.

154. A. Lahoz, D. Hernández, M. A. Miranda, J. Pérez-Prieto, I. M. Morera and J. V. Castell, Chem. Res. Toxicol., 2001, 14, 1486-1491.

155. J. Moser, Z. Sarabia, H. Minter, W. W. Lovell and G. M. J. Beijersbergen van Henegouwen, J. Photochem. Photobiol. B, 2000, 58, 37-45.

156. I. Andreu, C. Mayorga and M. A. Miranda, Curr. Opin. Allergy. Clin. Immunol., 2010, 10, 303-308.

157. F. Bosca, M. C. Cuquerella, M. L. Marin and M. A. Miranda, Photochem. Photobiol., 2001, 73, 463-468.

158. M. Nishijima, H. Kato, G. Fukuhara, C. Yang, T. Mori, T. Maruyama, M. Otagiri and Y. Inoue, Chem. Commun., 2013, 49, 7433-7435.

159. K. Bando, T. Zako, M. Sakono, M. Maeda, T. Wada, M. Nishijima, G. Fukuhara, C. Yang, T. Mori, T. C. S. Pace, C. Bohne and Y. Inoue, Photochem. Photobiol. Sci., 2010, 9, 655-660. 
160. M. Marin, V. Lhiaubet-Vallet, C. Paris, M. Yamaji and M. A. Miranda, Photochem. Photobiol. Sci., 2011, 10, 1474-1479.

161. M. Marin, V. Lhiaubet-Vallet and M. Angel Miranda, J. Phys. Chem. B, 2011, 115, 2910-2915.

162. M. Marin, V. Lhiaubet-Vallet and M. A. Miranda, Org. Lett., 2012, 14, 1788-1791.

163. M. Fukagawa, I. Kawamura, T. Ubukata and Y. Yokoyama, Chem. Eur. J., 2013, 19, 9434-9437. 


\section{Chart 1}
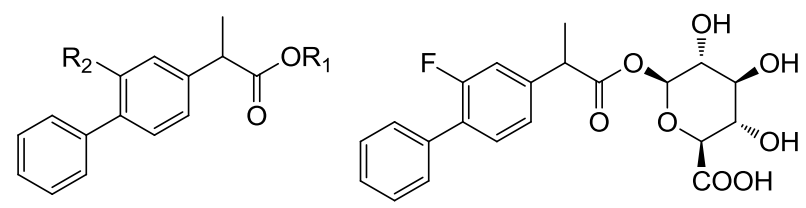<smiles>c1ccc2c(CC3=NCCN3)cccc2c1</smiles><smiles>COc1ccc2cc(C(C)C(=O)O)ccc2c1</smiles>

$\mathrm{R}_{1}=\mathrm{H}, \mathrm{R}_{2}=\mathrm{F}$ : FBP

$\mathrm{R}_{1}=\mathrm{CH}_{3}, \mathrm{R}_{2}=\mathrm{F}$ : FBP-Me

FBP-Gluc

NPZ

NPX

$\mathrm{R}_{1}=\mathrm{H}, \mathrm{R}_{2}=\mathrm{OH}: \mathrm{BOH}$<smiles>CC(NCCCc1cccc(C(F)(F)F)c1)c1cccc2ccccc12</smiles>

CIN<smiles>COc1ccc2cc(CCC(C)=O)ccc2c1</smiles>

NAB<smiles>CC(=O)c1ccc2ccccc2c1O</smiles>

HAN<smiles>C=CC(C)(C)c1cc(/C=C/C(=O)c2ccc(O)cc2)c(OC)cc1O</smiles>

LCA<smiles>CC(C(=O)O)c1cccc(C(=O)c2ccccc2)c1</smiles>

KPF<smiles>COc1ccc(C(=O)c2ccc(OC)cc2)cc1</smiles>

DMB<smiles>O=C(O)c1ccc(C(F)(F)F)cc1O</smiles>

HTB<smiles>[R]c1cc([R2])c(O)c(C(=O)O)c1</smiles><smiles>O=C(O)c1cc(C(=C2C=CC(=O)C(C(=O)O)C2)c2ccc(O)c(C(=O)O)c2)ccc1O</smiles>

ATA<smiles>COc1cc2ccc(=O)oc2c(OC)c1O</smiles>

ISF<smiles>COc1ccc(-c2coc3cc(O)ccc3c2=O)cc1</smiles>

FME

$\mathrm{R}_{1}=\mathrm{Cl}, \mathrm{R}_{2}=\mathrm{H}: \mathrm{CSA}$

$\mathrm{R}_{1}=\mathrm{Cl}, \mathrm{R}_{2}=\mathrm{Cl}$ : DSA<smiles>[R3]c1cc2oc(=O)ccc2c([R1])c1[R]</smiles><smiles>Cc1oc2c(C)c3oc(=O)cc(C)c3cc2c1N</smiles><smiles>COc1c2occc2cc2ccc(=O)oc12</smiles>

$\begin{array}{lll}\mathrm{R}_{1} & \mathrm{R}_{2} & \mathrm{R}_{3}\end{array}$

PIR

$\begin{array}{cccc}\text { 6,7-DMC } & \mathrm{H} & \mathrm{OCH}_{3} & \mathrm{OCH}_{3} \\ 5,7-\mathrm{DMC} & \mathrm{OCH}_{3} & \mathrm{H} & \mathrm{OCH}_{3}\end{array}$

ATM

8-MOP 
<smiles>CCn1cc(C(=O)O)c(=O)c2ccc(C)nc21</smiles><smiles>[Y]c1c(N2CCN([R2])C([R3])C2)c(F)cc2c(=O)c(C(=O)O)cn([R])c12</smiles>

$\mathrm{R}_{1}$ ENO $\mathrm{CH}_{2} \mathrm{CH}_{3}$ $\begin{array}{lll}\mathrm{X} & \mathrm{R}_{2} & \mathrm{R}_{3}\end{array}$ $\begin{array}{llllll}\mathrm{NOR} & \mathrm{CH}_{2} \mathrm{CH}_{3} & \mathrm{CH} & \mathrm{H} & \mathrm{H}\end{array}$ CIP $\mathrm{CH}\left(\mathrm{CH}_{2} \mathrm{CH}_{2}\right) \quad \mathrm{CH} \quad \mathrm{H} \quad \mathrm{H}$ OFL $\quad \mathrm{CH}\left(\mathrm{CH}_{3}\right) \mathrm{CH}_{2} \mathrm{OC} \quad \mathrm{CH}_{3} \mathrm{H}$ $\begin{array}{lllll}\mathrm{LOM} & \mathrm{CH}_{2} \mathrm{CH}_{3} & \mathrm{CF} & \mathrm{H} & \mathrm{CH}_{3}\end{array}$<smiles>CC(C(=O)O)c1ccc2c(c1)[nH]c1ccc(Cl)cc12</smiles>
CPF<smiles>O=C(O)Cc1c2ccccc2cc2ccccc12</smiles>

ANA<smiles>C=CC1CC2CCN1CC2[C@H](O)c1ccnc2ccc(OC)cc12</smiles>

QIN<smiles>CCN(CC)CCCC(C)Nc1c2ccc(Cl)cc2nc2ccc(OC)cc12</smiles>

QIC<smiles>CC(C(=O)O)c1c2ccccc2cc2ccccc12</smiles>

ANP<smiles>O=C(O)c1ccc2cc3ccccc3cc2c1</smiles>

ANC<smiles>Cc1cc2cc3cc(C)c(N)cc3nc2cc1N</smiles><smiles>[R]c1nccc2c1[nH]c1ccccc12</smiles><smiles>O=C(O)c1c(Cl)c(Cl)c(Cl)c(Cl)c1-c1c2cc(I)c(=O)c(I)c-2oc2c(I)c(O[N+](=O)[O-])c(I)c(Cl)c12</smiles>
ACY PFL $\mathrm{R}=\mathrm{H}: \mathrm{NOR}$<smiles>CC(CCC(=O)O)[C@H]1CCC2C3C(NS(=O)(=O)c4cccc5c(N(C)C)cccc45)CC4C[C@@H](O)CC[C@]4(C)C3C[C@H](O)[C@@]21C</smiles>

3-DNS-CHA<smiles>CN(C)[C@H]1C(O)=C(C(N)=O)C(=O)[C@]2(O)C(O)=C3C(=O)c4c(O)cccc4[C@@](C)(O)C3C[C@H]12</smiles>

$\mathrm{TCH}$ 
<smiles>[X]C1=C(O)C(=C2C(=O)C(c3c(O)c([X])c(O)c([X])c3O)C2O)C(O)=C([X])C1=O</smiles>

$\mathrm{X}=\mathrm{H}: \mathrm{SQD}$

$\mathrm{X}=\mathrm{Br}$ : SQB

$\mathrm{X}=\mathrm{I}$ : SQI<smiles></smiles>

$\mathrm{R}_{1}=\mathrm{COCH}_{3}, \mathrm{R}_{2}=\mathrm{CH}_{3}: \mathrm{COL}$

$\mathrm{R}_{1}=\mathrm{COCH}_{3}, \mathrm{R}_{2}=\mathrm{H}$ : CEI<smiles>COc1ccc(C(=O)CC(=O)c2ccc(C(C)(C)C)cc2)cc1</smiles>

ABZ

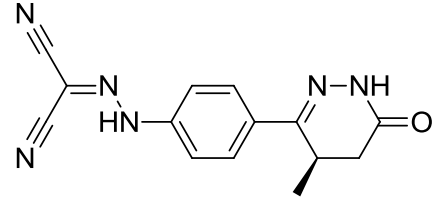

LSM<smiles>CCCCNC1CCc2cc(OC)c(OC)c(OC)c2C2C(OC)=CC2C2=C1C(=O)C(OC)=C2</smiles>

LCL<smiles>CCCC(C(=O)c1ccc(OC)cc1)C(=O)c1ccc(C(C)(C)C)cc1</smiles>

$\mathrm{PAB}$<smiles>Cc1cc2nc3[nH]c(=O)[nH]c(=O)c3nc2cc1C</smiles>

$\mathrm{LCH}$<smiles>Oc1ccc2ccccc2c1-c1c(O)ccc2ccccc12</smiles>

BNP

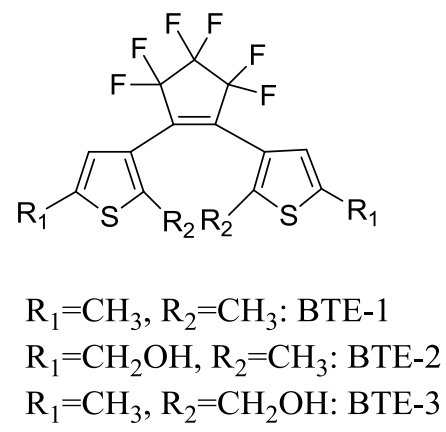<smiles>CN(c1ccccc1)c1ccccc1</smiles>

DPA

$\mathrm{R}=\mathrm{CH}_{3}: \mathrm{MNA}$

$\mathrm{R}=\left(\mathrm{CH}_{2}\right)_{3} \mathrm{COOH}: \mathrm{MNG}$ 
Figures and Figure Legends
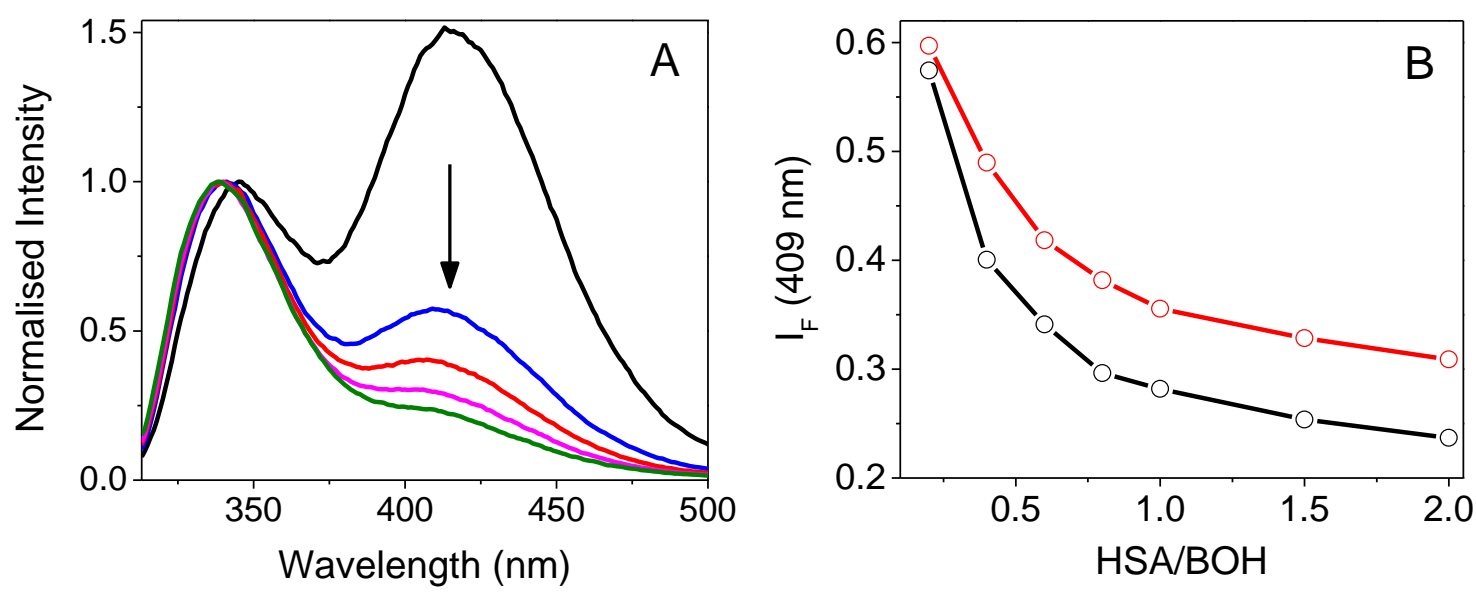

Figure 1. (A) Fluorescence spectra (normalised at the short-wavelength maximum) of ( $S$ )-BOH in PBS $\left(\lambda_{\mathrm{exc}}=308 \mathrm{~nm}\right.$, air, $\left.10^{-4} \mathrm{M}\right)$ after addition of increasing amounts of HSA. The $(S)$ BOH/HSA molar ratios are 1:0 (black), 1:0.2 (blue), 1:0.4 (red), 1:0.8 (magenta), and 1:2 (green). (B) Plot of the fluorescence intensity at $409 \mathrm{~nm}$ vs $\mathrm{HSA} / \mathrm{BOH}$ molar ratio for $(S)-\mathrm{BOH}$ (black) and (R)-BOH (red). Adapted with permission from J. Phys. Chem. B, 2012, 116, 1483914843. Copyright 2012 American Chemical Society. 


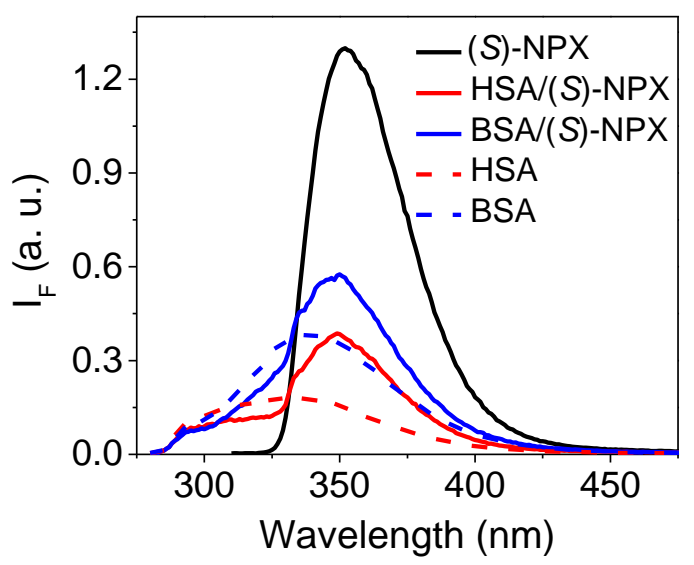

Figure 2. Fluorescence spectra of HSA, BSA, $(S)$-NPX, $(S)$-NPX/HSA and $(S)$-NPX/BSA (complexes at 1:1 molar ratio). All the experiments were carried out in PBS/air. The absorbance of the samples is 0.1 at the excitation wavelength $(266 \mathrm{~nm})$. This corresponds to concentrations in the order of $10^{-5}$ M. Adapted with permission from Chem. Phys. Lett., 2010, 486, 147-153, Copyright 2010 Elsevier. 


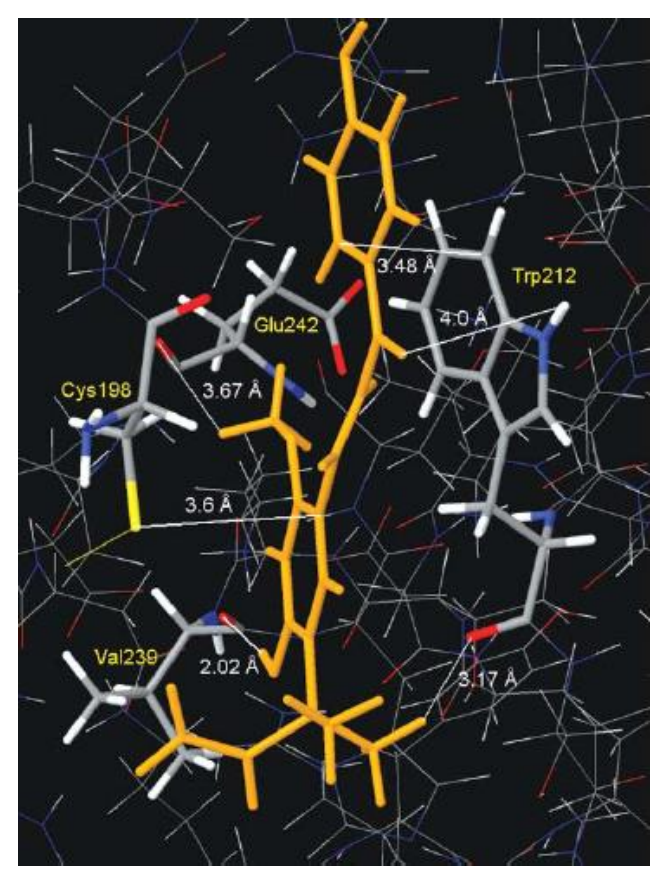

Figure 3. Docking of LCA in domain IIA of BSA. Reproduced from Ref. 57 with permission from the European Society for Photobiology, the European Photochemistry Association, and The Royal Society of Chemistry. 

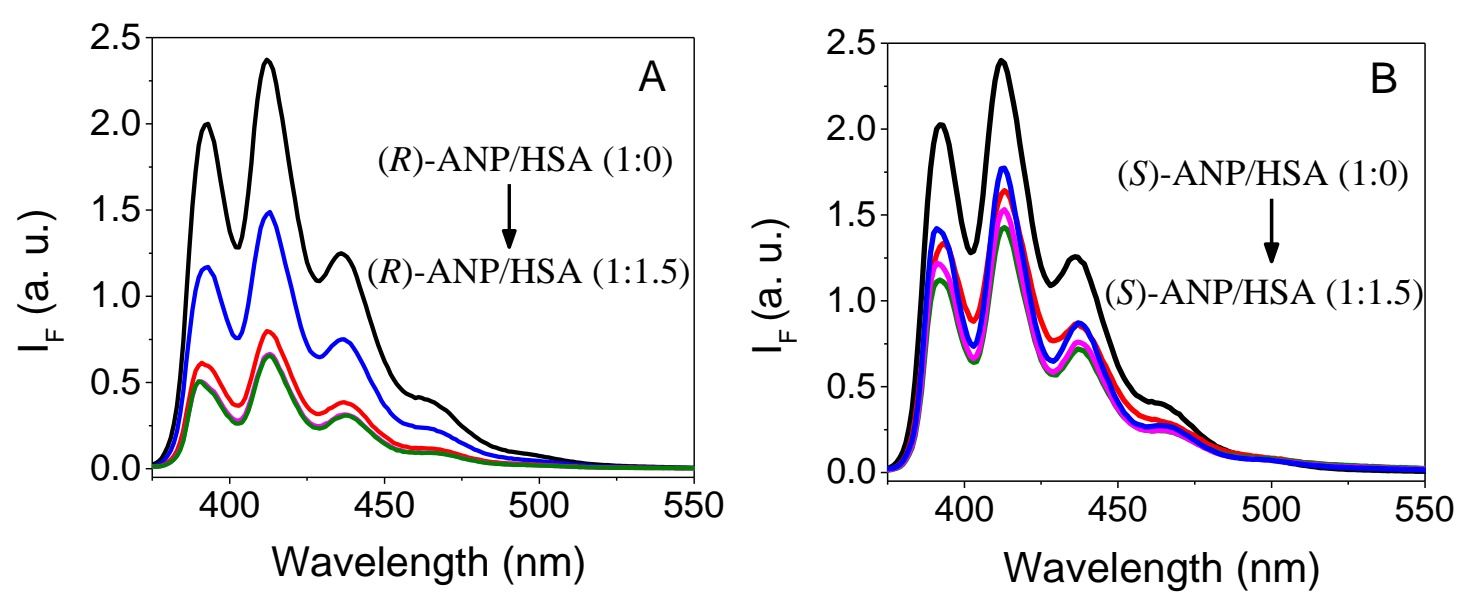

Figure 4. Fluorescence spectra of ANP in the presence of increasing amounts of HSA, up to a 1:1.5 molar ratio for (A) (R)-ANP and (B) (S)-ANP. Adapted with permission from Org. Lett., 2011, 13, 3860-3863. Copyright 2011 American Chemical Society. 

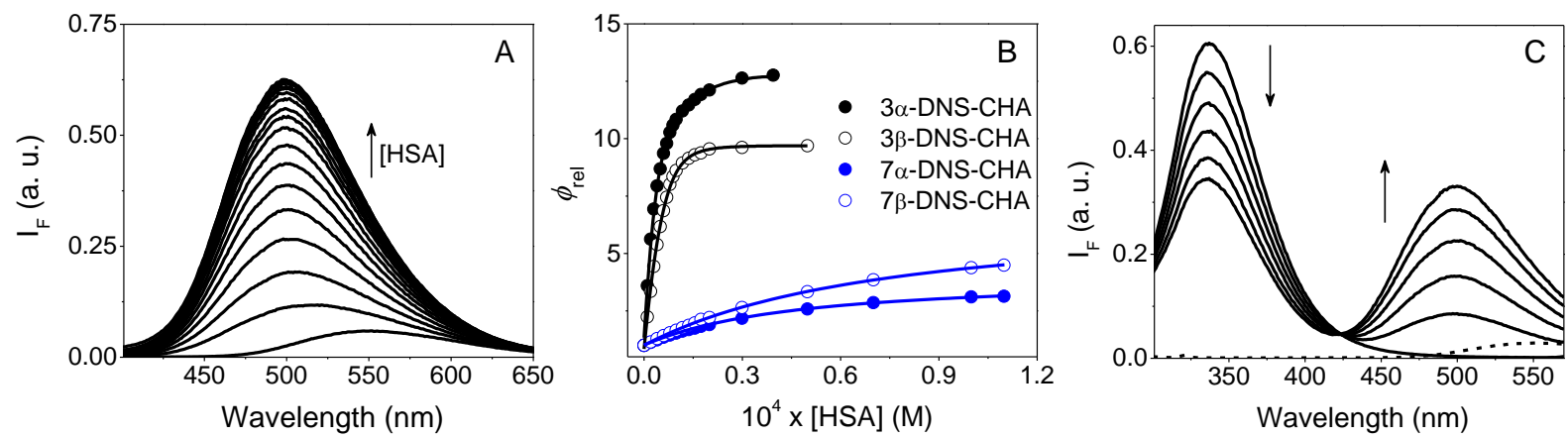

Figure 5. (A) Emission spectra $\left(\lambda_{\mathrm{exc}}=340 \mathrm{~nm}\right)$ of $3 \beta$-DNS-CHA in PBS $(10 \mu \mathrm{M})$ upon addition of increasing concentrations of HSA $(0-50 \mu \mathrm{M})$. (B) Changes in the relative fluorescence quantum yield $\left(\phi_{\text {rel }}=\phi / \phi_{0}\right)$ of all DNS derivatives plotted against the HSA concentration with the corresponding fittings. (C) Emission spectra of HSA in PBS $(20 \mu \mathrm{M})$ upon addition of increasing amounts of $3 \beta$-DNS-CHA (up to $20 \mu \mathrm{M}$ ). The dashed line corresponds to a blank experiment with the highest guest concentration in the absence of HSA, $\lambda_{\mathrm{exc}}=290 \mathrm{~nm}$. Adapted with permission from J. Phys. Chem. B, 2011, 115, 10518-10524. Copyright 2011 American Chemical Society. 


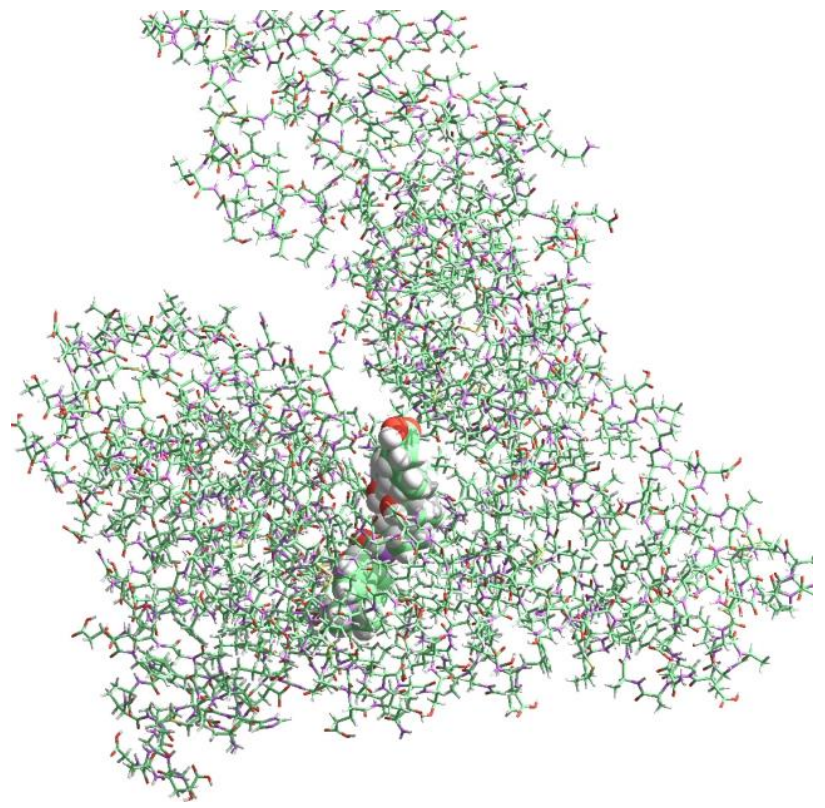

Figure 6. Minimum energy conformation of interaction between $3 \beta$-DNS-CHA (balls) and site 1 of HSA (sticks). Reprinted with permission from J. Phys. Chem. B, 2011, 115, 10518-10524. Copyright 2011 American Chemical Society. 


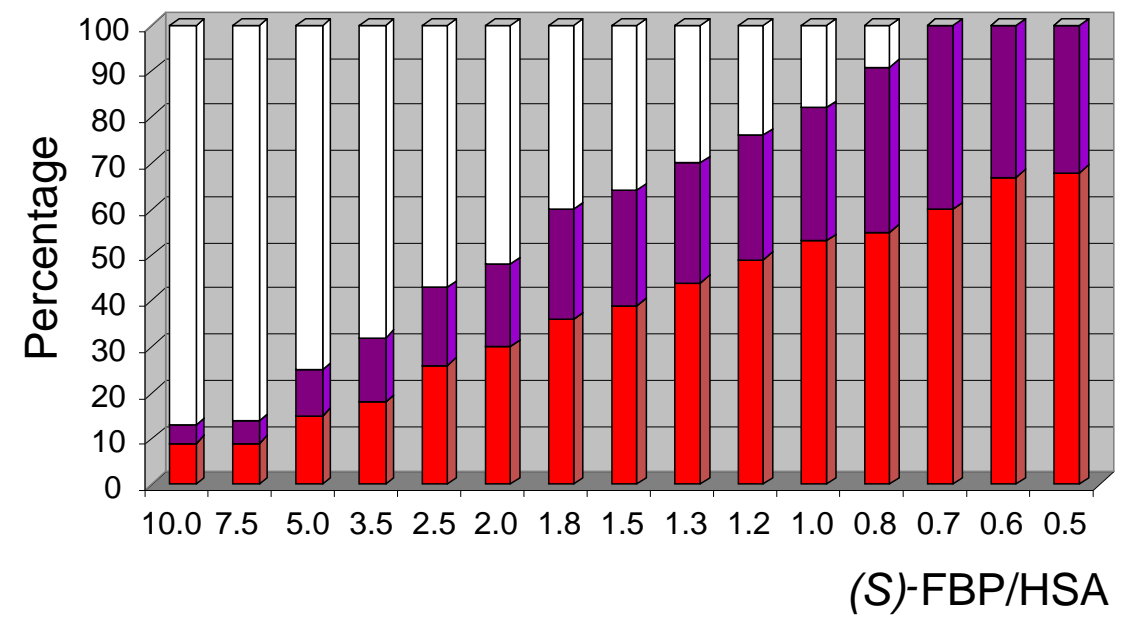

Figure 7. Percentage of free (white), site I- (violet) and site II-bound (red) $(S$ )-FBP in the presence of HSA at different $(S)$-FBP/HSA ratios. ${ }^{123}$ 

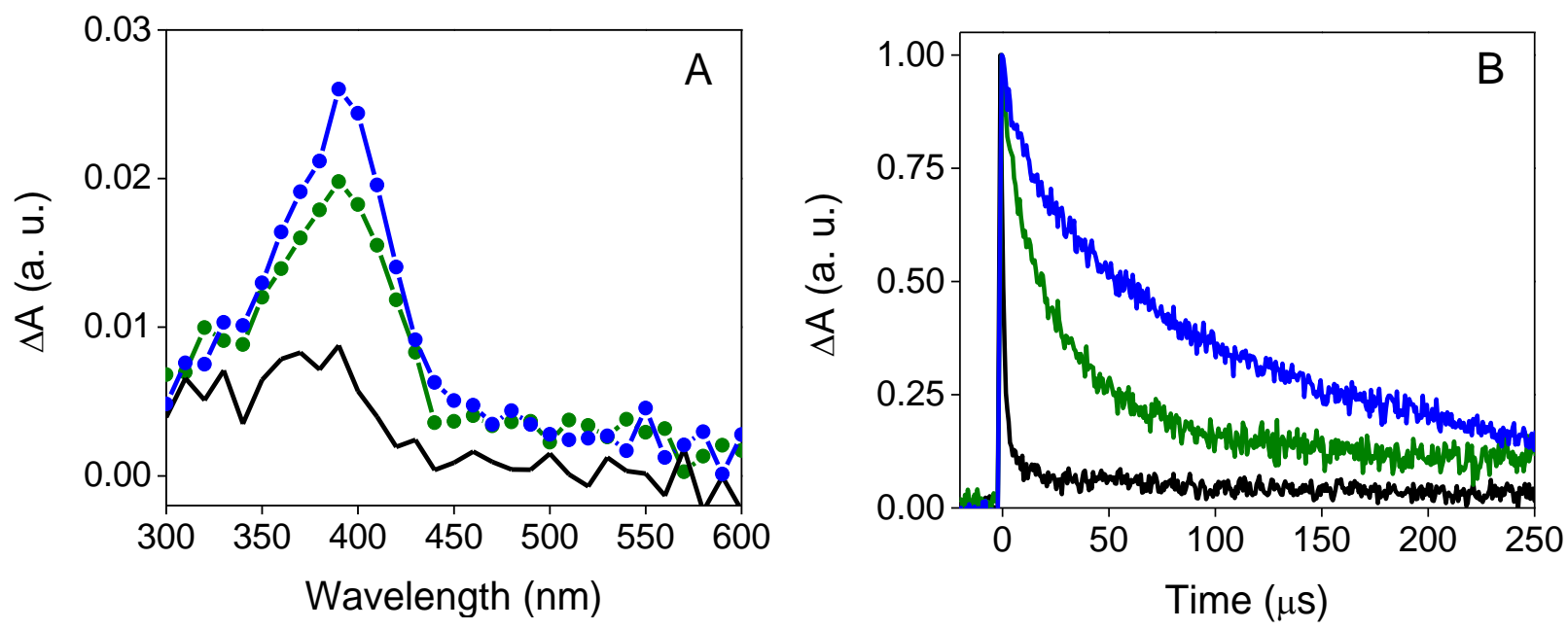

Figure 8. Laser flash photolysis ( $\lambda_{\mathrm{exc}}=266 \mathrm{~nm}$ ) of $2.5 \times 10^{-5} \mathrm{M}$ FBP-Me (black), as well as 1:1 solutions of $(S)$-FBP-Me/HSA (green) and $(R)$-FBP-Me/HSA (blue) in $0.01 \mathrm{M}$ PBS, under air. (A) Spectra obtained $3.7 \mu \mathrm{s}$ after the laser pulse. (B) Normalised decays monitored at $360 \mathrm{~nm}$. Adapted with permission from J. Am. Chem. Soc., 2005, 127, 10134-10135. Copyright 2005 American Chemical Society. 

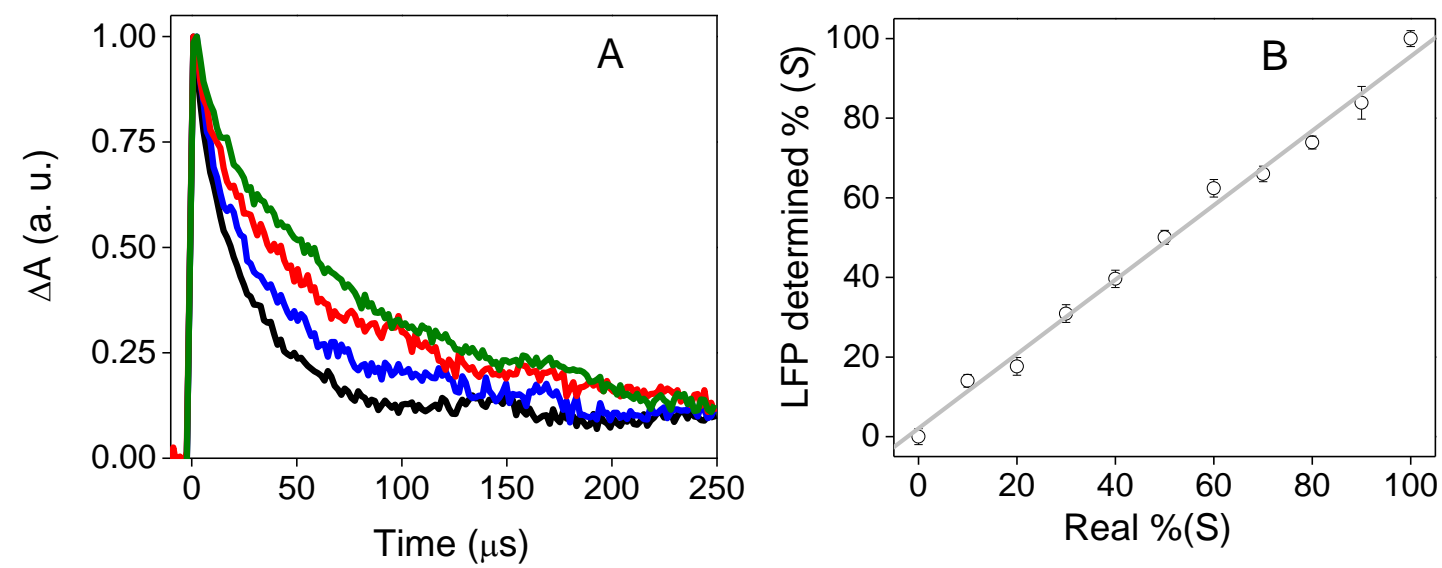

Figure 9. (A) Normalised decays $(\lambda=360 \mathrm{~nm})$ for several $(S)$-FBP-Me/(R)-FBP-Me/HSA mixtures: 1:0:1 (black), 0.7:0.3:1 (blue), 0.3:0.7:1 (red), and 0:1:1 (green) after LFP at $266 \mathrm{~nm}$. (B) LFP-determined values against known real values, together with the linear fit of the experimental points. Adapted with permission from Chem. Eur. J., 2008, 14, 11284-11287. Copyright 2008 Wiley. 


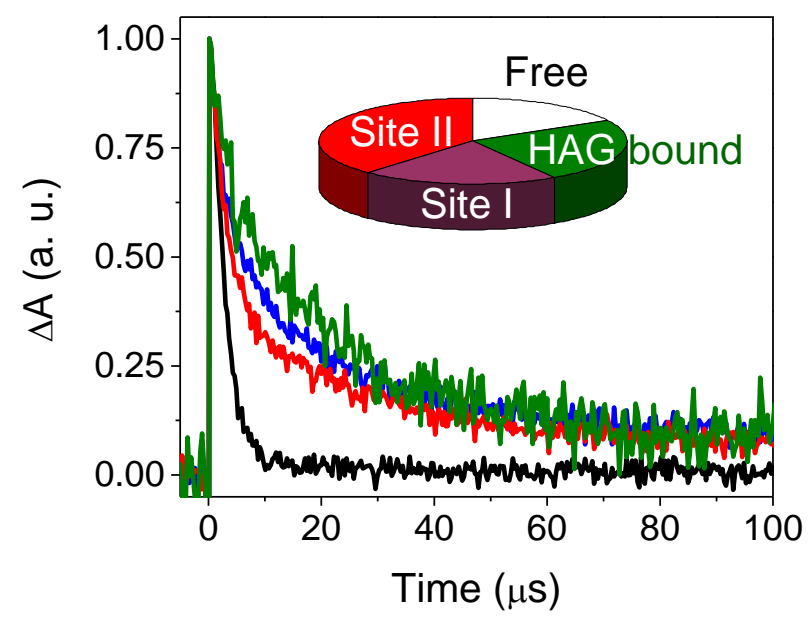

Figure 10. Decays for $(R)$-CIN $\left(10^{-4} \mathrm{M}\right.$, PBS $0.01 \mathrm{M}, \mathrm{pH}=7.4, \lambda_{\mathrm{exc}}=266 \mathrm{~nm}, \lambda_{\mathrm{em}}=420 \mathrm{~nm}$, air) in the presence of human proteins. Inset: distribution of $(R)$-CIN in the different compartments, determined from the preexponential factors of the fitting curves. Adapted with permission from J. Phys. Chem. B, 2011, 115, 4460-4468. Copyright 2011 American Chemical Society. 


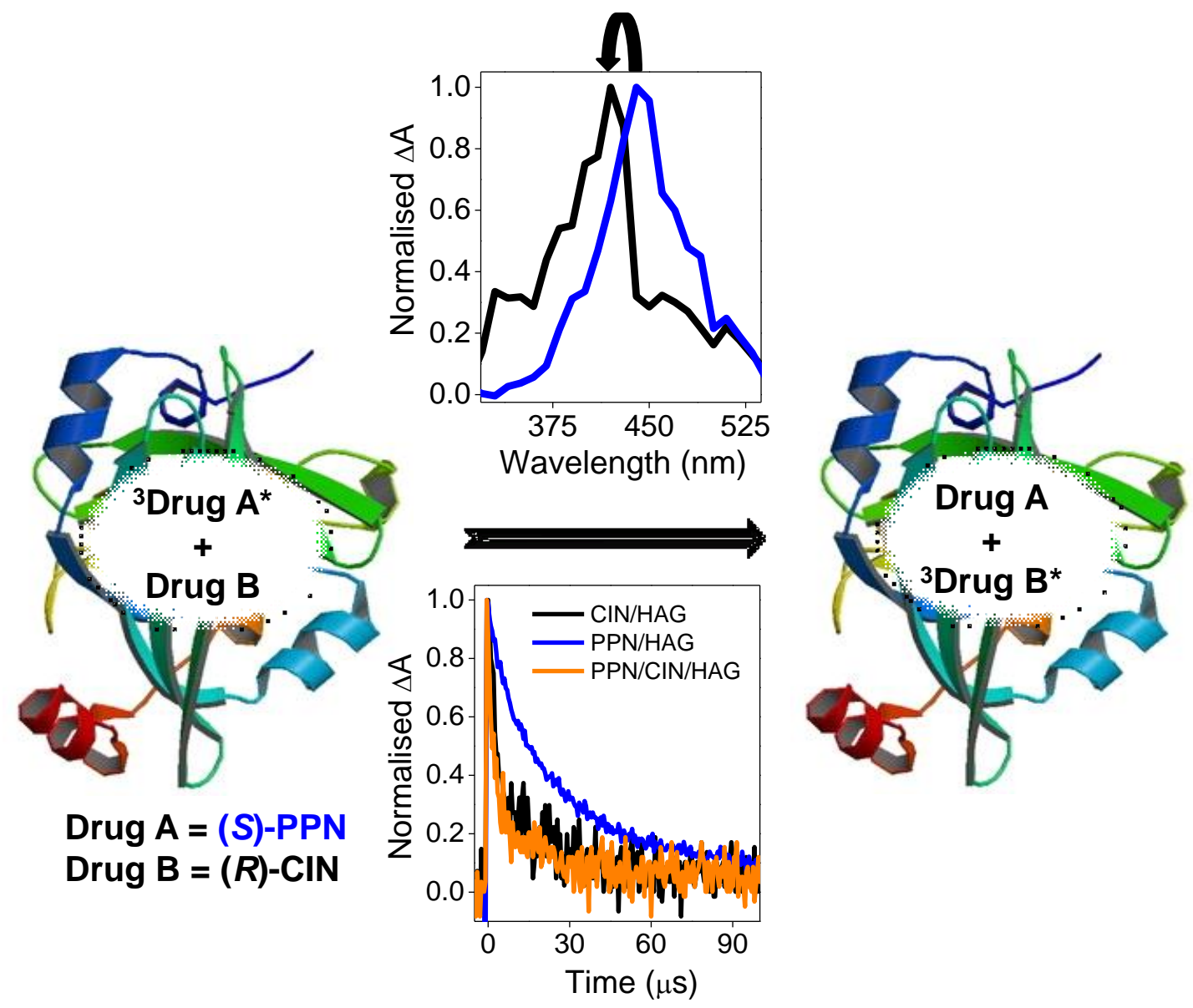

Figure 11. Representation of the use of TTEnT to detect DDI between two drugs sharing a common protein binding site. Laser flash photolysis $\left(\lambda_{\mathrm{exc}}=308 \mathrm{~nm}\right.$, PBS/air) of CIN/PPN systems. Normalised spectra and decay traces $\left(\lambda_{\max }=450 \mathrm{~nm}\right)$ for CIN/HAG (black), PPN/HAG (blue) and CIN/PPN/HAG (orange). The concentration of each component is $5.8 \times 10^{-4} \mathrm{M}$. Adapted with permission from J. Phys. Chem. Lett., 2013, 4, 1603-1607. Copyright 2013 American Chemical Society. 


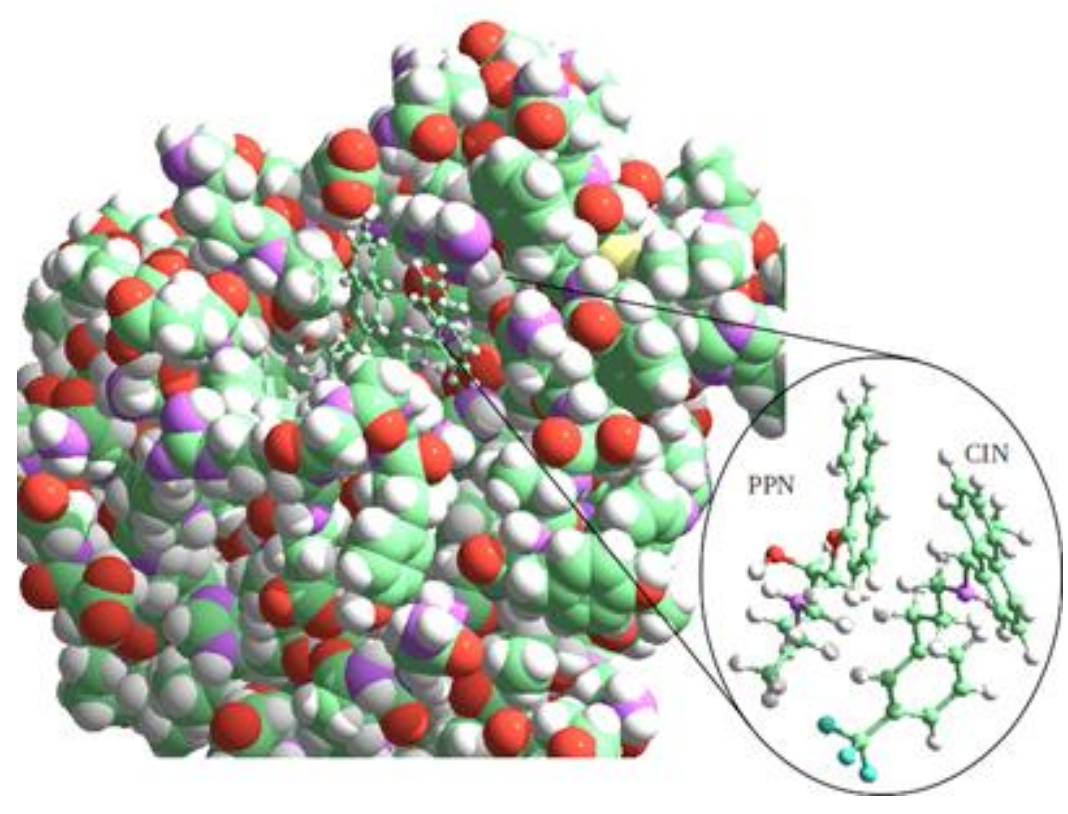

Figure 12. Optimised geometry of PPN and CIN within the binding site of HAG. Adapted with permission from J. Phys. Chem. Lett., 2013, 4, 1603-1607. Copyright 2013 American Chemical Society. 

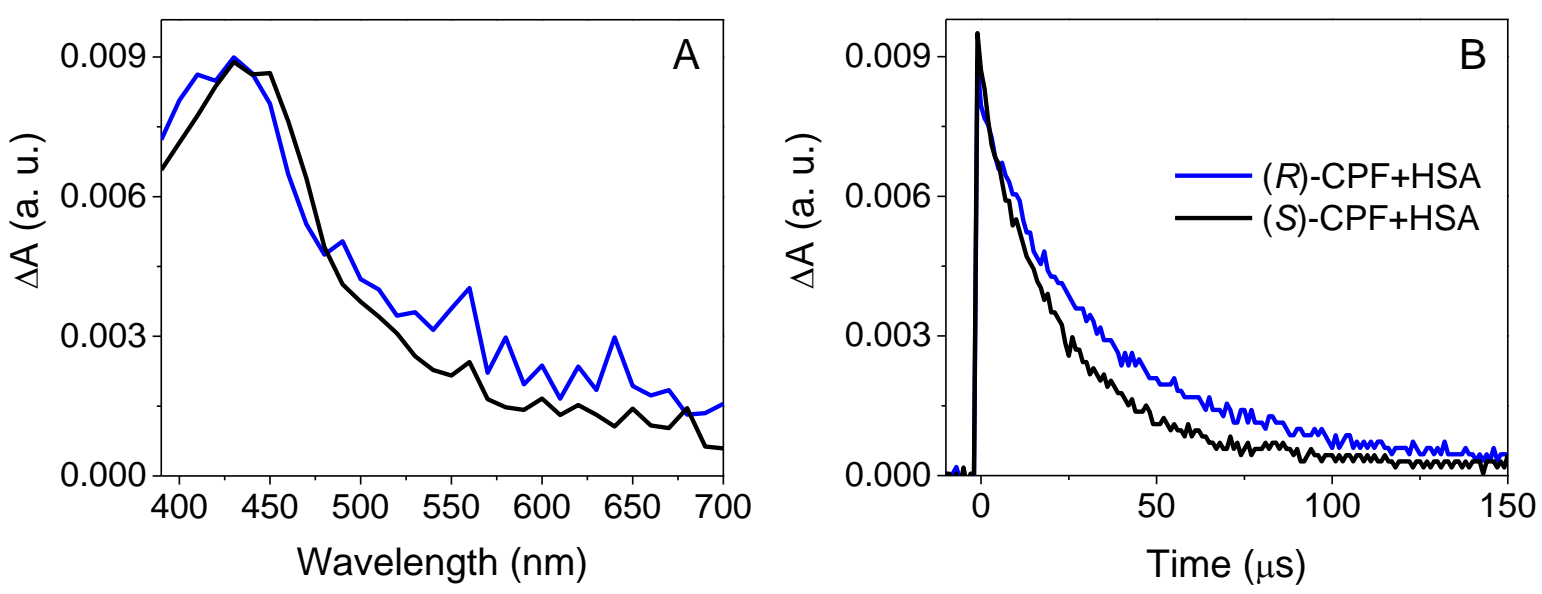

Figure 13. (A) Transient absorption spectra obtained $5 \mu$ s after the laser pulse $\left(\lambda_{\text {exc }}=308 \mathrm{~nm}\right)$ and (B) decays monitored at $450 \mathrm{~nm}$ of anaerobic buffered solutions of equimolar mixtures of $(R)-\mathrm{CPF} / \mathrm{HSA}$ (blue) and (S)-CPF/HSA (black). Adapted with permission from J. Am. Chem. Soc., 2004, 126, 9538-9539. Copyright 2004 American Chemical Society. 

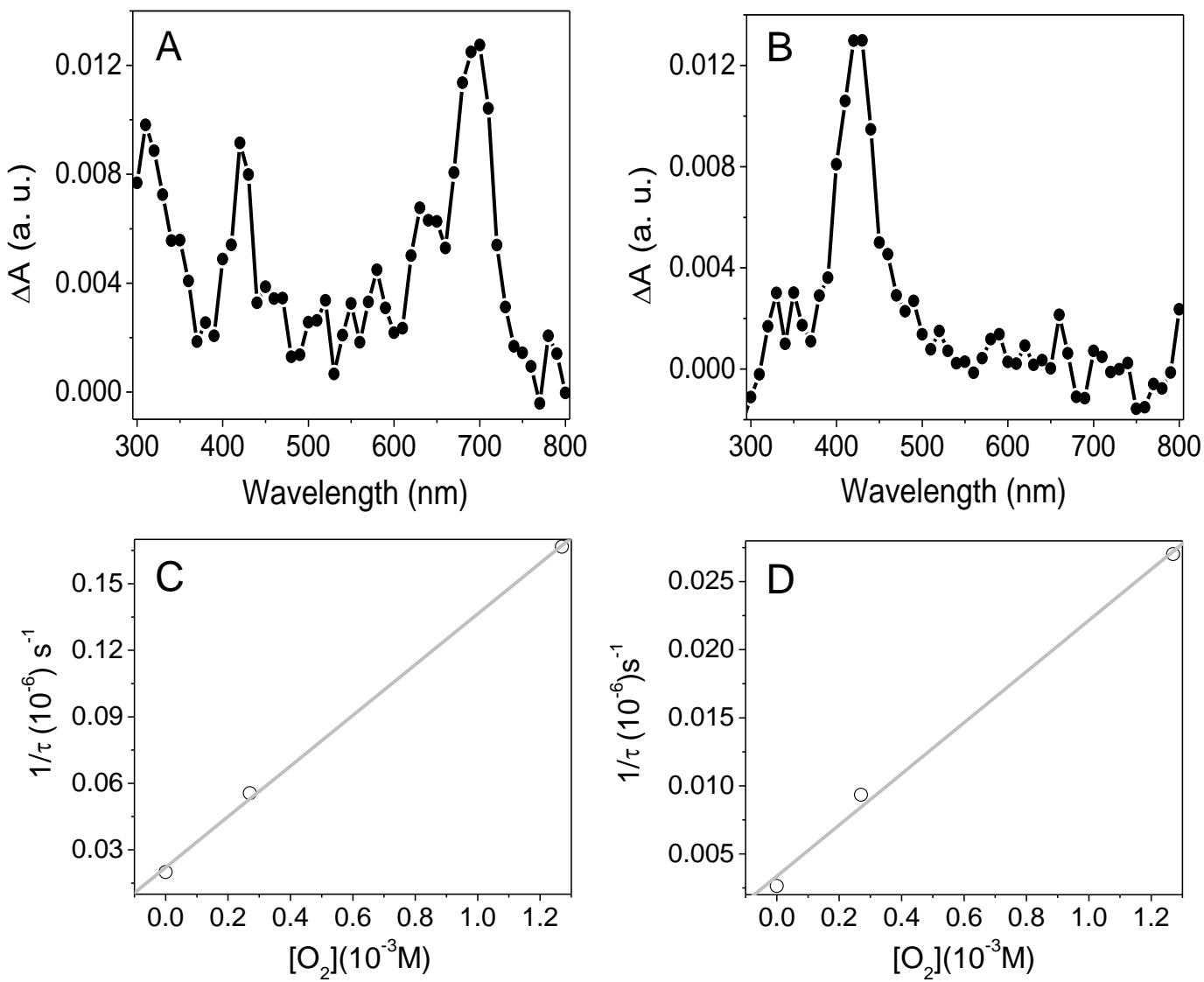

Figure 14. Laser flash photolysis in PBS, under air at $\lambda_{\mathrm{exc}}=355 \mathrm{~nm}$. Transient absorption spectra of $(S)$-ANP in the absence (A) and in the presence of HSA, at 1:1 molar ratio (B), recorded $1 \mu \mathrm{s}$ and $2.9 \mu$ s after laser pulse, respectively. Stern-Volmer plots for quenching of the (S)-ANP triplet state by oxygen in site I (C) or in site II (D) of HSA. Adapted with permission from Org. Lett., 2011, 13, 3860-3863. Copyright 2011 American Chemical Society. 

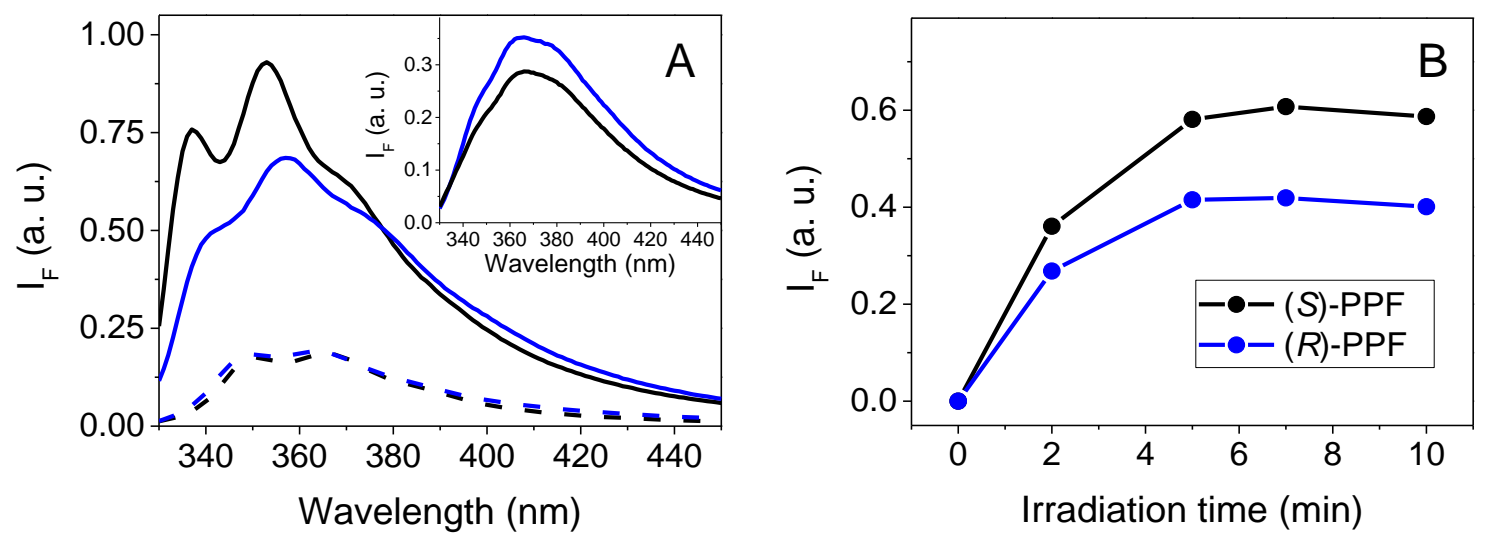

Figure 15. (A) Fluorescence spectra $\left(\lambda_{\text {exc }}=320 \mathrm{~nm}\right)$ of aerated $(S)$-CPF/HSA (black) and $(R)$ $\mathrm{CPF} / \mathrm{HSA}$ (blue) at a molar ratio of 1 before (dash line) and after (solid line) UVA irradiation. Inset: photobinding of CPF enantiomers with HSA monitored by fluorescence after UVA irradiation and subsequent sephadex filtration. (B) Formation of PPF enantiomers upon UVA irradiation of racemic CPF@HSA. Adapted with permission from J. Phys. Chem. B, 2007, 111, 423-431. Copyright 2007 American Chemical Society. 


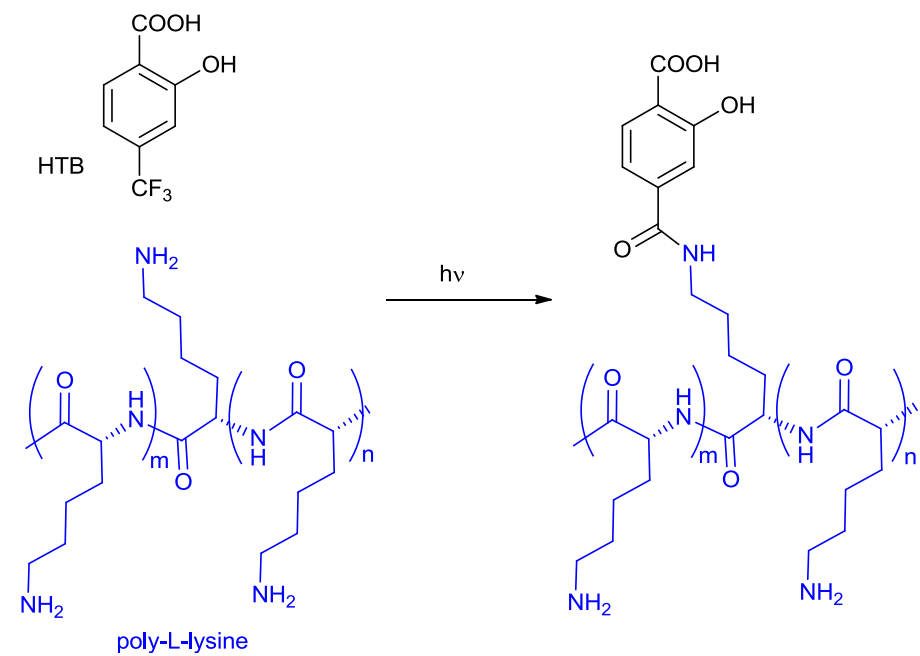

Figure 16. Photobinding of HTB to poly-L-lysine. 


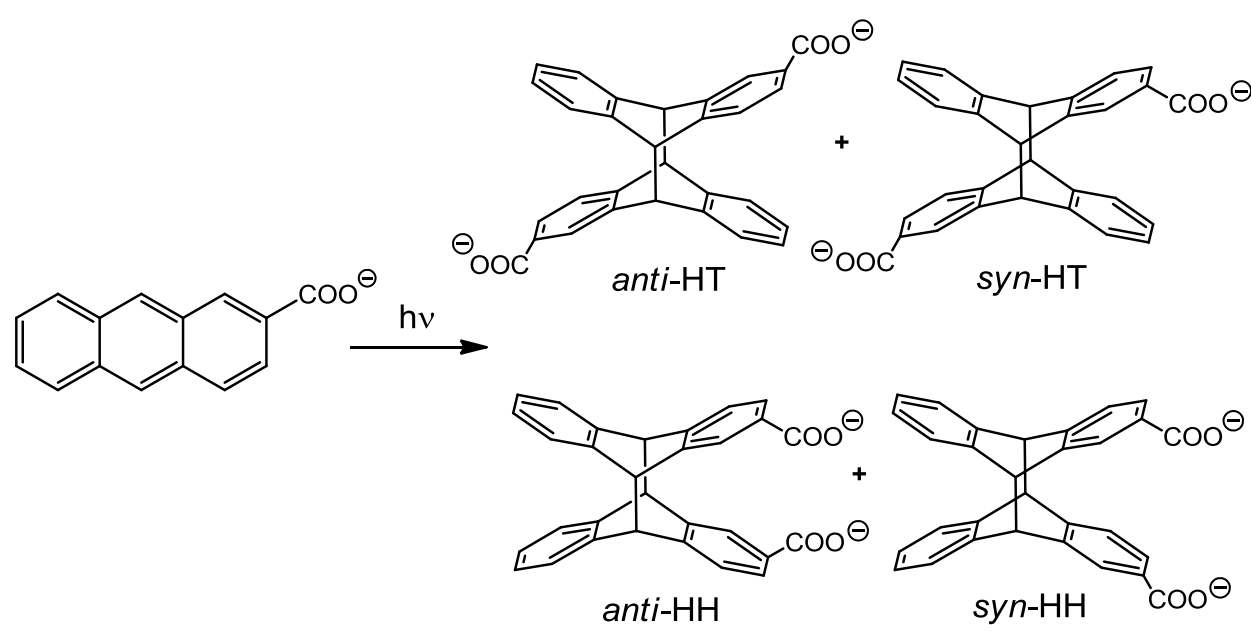

Figure 17. Photoproducts resulting from the [4+4] photocycloaddition of ANC. 


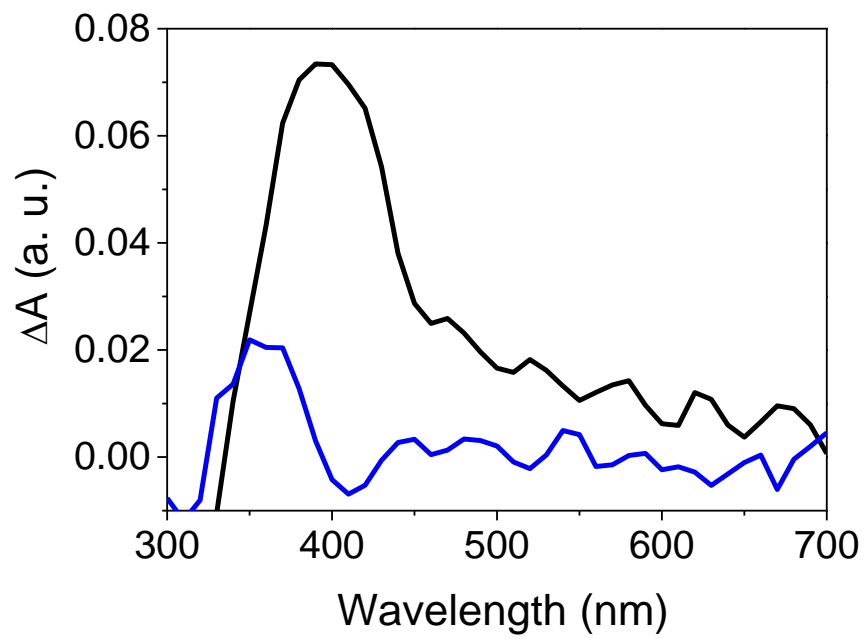

Figure 18. Laser flash photolysis spectra of PAB@HSA (molar ratio of $1 ; 2.5 \times 10^{-4} \mathrm{M}$ ) in aerated PBS registered $0.5 \mu$ s (black) and $40 \mu$ s (blue) after the $308 \mathrm{~nm}$ laser pulse. Reproduced from Ref. 160 with permission from the European Society for Photobiology, the European Photochemistry Association, and The Royal Society of Chemistry. 


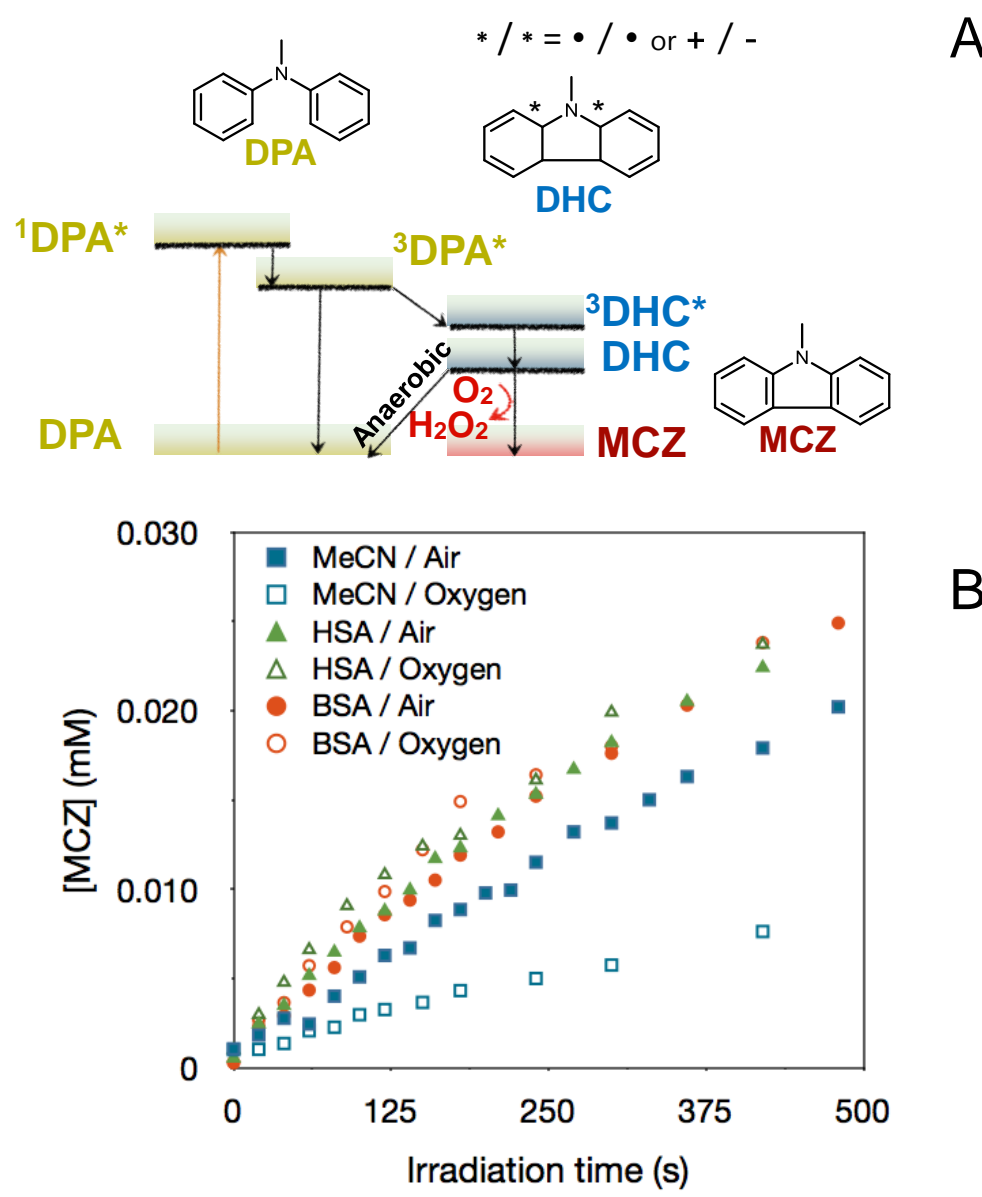

Figure 19. (A) Diagram of the reaction mechanism with the structures of $\mathrm{N}$ methyldiphenylamine (DPA), $N$-methyl-4a,4b-dihydrocarbazole (DHC), and $N$-methylcarbazole (MCZ). (B) CBZ concentration plotted as a function of irradiation time for DPA free in acetonitrile $\left(8.25 \times 10^{-5} \mathrm{M}\right)$ and encapsulated in HSA or BSA (at DPA/SA molar ratio of 1) under aerated or oxygen bubbled conditions. Adapted with permission from Org. Lett., 2012, 14, 1788-1791. Copyright 2012 American Chemical Society. 


\section{Equations}

$\Delta \mathrm{A}=\Delta \mathrm{A}_{0}+\mathrm{A}_{\mathrm{F}} \times \mathrm{e}^{\left(\mathrm{t} / \tau_{\mathrm{F}}\right)}$

Eq. 1

$\Delta \mathrm{A}=\Delta \mathrm{A}_{0}+\mathrm{A}_{\mathrm{I}} \times \mathrm{e}^{\left(-\mathrm{t} / \tau_{\mathrm{I}}\right)}+\mathrm{A}_{\mathrm{II}} \times \mathrm{e}^{\left(-\mathrm{t} / \tau_{\mathrm{II}}\right)}$

Eq. 2

$\Delta \mathrm{A}=\Delta \mathrm{A}_{0}+\mathrm{A}_{\mathrm{F}} \times \mathrm{e}^{\left(-\mathrm{t} / \tau_{\mathrm{F}}\right)}+\mathrm{A}_{\mathrm{I}} \times \mathrm{e}^{\left(-\mathrm{t} / \tau_{\mathrm{I}}\right)}+\mathrm{A}_{\mathrm{II}} \times \mathrm{e}^{\left(-\mathrm{t} / \tau_{\mathrm{II}}\right)}$

Eq. 3

$\Delta \mathrm{A}=\Delta \mathrm{A}_{0}+\mathrm{A}_{\mathrm{F}} \times \mathrm{e}^{\left(-\mathrm{t} / \tau_{\mathrm{F}}\right)}+\mathrm{A}_{\mathrm{B}} \times \mathrm{e}^{\left(-\mathrm{t} / \tau_{\mathrm{B}}\right)}$

Eq. 4

$\Delta \mathrm{A}=\Delta \mathrm{A}_{0}+\mathrm{A}_{\mathrm{F}} \times \mathrm{e}^{\left(-\mathrm{t} / \tau_{\mathrm{F}}\right)}+\mathrm{A}_{\mathrm{I}} \times \mathrm{e}^{\left(-\mathrm{t} / \tau_{\mathrm{I}}\right)}+\mathrm{A}_{\mathrm{II}} \times \mathrm{e}^{\left(\mathrm{-t} / \tau_{\mathrm{II}}\right)}+\mathrm{A}_{\mathrm{B}} \times \mathrm{e}^{\left(\mathrm{-} \mathrm{t} / \tau_{\mathrm{B}}\right)}$

Eq. 5

$\Delta \mathrm{A}=\Delta \mathrm{A}_{0}+\mathrm{A}_{\mathrm{I}}^{\mathrm{S}} \times \mathrm{e}^{\left(-\mathrm{t} / \tau_{\mathrm{I}}^{\mathrm{S}}\right)}+\mathrm{A}_{\mathrm{II}}^{\mathrm{S}} \times \mathrm{e}^{\left(-\mathrm{t} / \tau_{\mathrm{II}}^{\mathrm{S}}\right)}+\mathrm{A}_{\mathrm{I}}^{\mathrm{R}} \times \mathrm{e}^{\left(-\mathrm{t} / \tau_{I}^{\mathrm{R}}\right)}+\mathrm{A}_{\mathrm{II}}^{\mathrm{R}} \times \mathrm{e}^{\left(-\mathrm{t} / \tau_{\mathrm{II}}^{\mathrm{R}}\right)}$

Eq. 6

$\Delta \mathrm{A}=\Delta \mathrm{A}_{0}+\mathrm{A}_{\mathrm{F}} \times \mathrm{e}^{\left(\mathrm{t} / \tau_{\mathrm{F}}^{\mathrm{EBP}-\text { Gluc }}\right)}+\mathrm{A}_{\mathrm{B}} \times \mathrm{e}^{\left(\mathrm{-t} / /_{\mathrm{B}}^{\mathrm{EPP}-\text { Gluc }}\right)}+\mathrm{A}_{\mathrm{I}} \times \mathrm{e}^{\left(\mathrm{t} / \tau_{\mathrm{I}}^{\mathrm{EBP}}\right)}+\mathrm{A}_{\mathrm{II}} \times \mathrm{e}^{\left(-\mathrm{t} / \tau_{\mathrm{II}}^{\mathrm{EPP}}\right)}$

Eq. 7

$\Delta \mathrm{A}=\Delta \mathrm{A}_{0}+\mathrm{A}_{\mathrm{F}}^{\mathrm{T}} \times \mathrm{e}^{\left(-\mathrm{t} / \tau_{\mathrm{F}}^{\mathrm{T}}\right)}+\mathrm{A}_{\mathrm{B}}^{\mathrm{T}} \times \mathrm{e}^{\left(-\mathrm{t} / \tau_{\mathrm{B}}^{\mathrm{T}}\right)}+\mathrm{A}_{\mathrm{F}}^{\mathrm{RC}} \times \mathrm{e}^{\left(-\mathrm{t} / \tau_{\mathrm{F}}^{\mathrm{RC}}\right)}$

Eq. 8 


\section{Biographies}

Ignacio Vayá is currently working at the Department of Chemistry at the Technical University of Valencia as a post-doctoral researcher (Juan de la Cierva program). He earned his Ph.D. in Chemistry at the Technical University of Valencia in 2007. In 2008, he started working at the Francis Perrin Laboratory as a postdoctoral fellow supported by the French National Research Agency and continued as a laureate of a grant from the Consellería de Educación-Generalitat Valenciana until april 2012 (VALi+D program). His research is focused in the photochemical reactivity and photophysical properties of drug-biomolecule systems by spectroscopic techniques.

Virginie Lhiaubet-Vallet received her PhD degree in 2001 from the University Paul Sabatier (Toulouse, France), working on DNA damage photoinduced by nonsteroidal anti-inflammatory drugs. Next, she obtained an Individual Marie Curie European Fellowship to join Prof. M. A. Miranda's group as a postdoctoral researcher at the Institute of Chemical Technology (UPVCSIC). In 2007, she was awarded for the Young Investigator Award from the European Society for Photobiology. Since 2008, she is a "Ramón y Cajal" Researcher from Spanish National Research Council at the Institute of Chemical Technology. Her research interests are mainly focused on the interaction between drugs and biomolecules.

M. Consuelo Jiménez is currently Full Professor of Organic Chemistry and Head of the Department of Chemistry at the Technical University of Valencia. She obtained her PhD from the Technical University of Valencia in 1997 under the supervision of Profs. Miguel A. Miranda and Rosa Tormos and was a "Marie Curie" post-doctoral fellow at Louis Pasteur University (Strasbourg) in 1999-2000 with J.-P. Sauvage, working on molecular motions, and a visiting professor at CEA (Saclay) in 2011 (femtosecond fluorescence). Her main research activity is focused on Organic Photochemistry, with particular interest in the study of xenobioticbiomolecule interactions using photophysical techniques.

Miguel A. Miranda is Full Professor of Organic Chemistry at the Technical University of Valencia and Head of the Institute of Chemical Technology (UPV-CSIC). He was post-doctoral researcher at the Universities of Saarland and Wuerzburg and associate Professor at the University of Valencia, before accepting his present position in 1990. He has received the Honda-Fujishima Award of the Japanese Photochemistry Association, the Organic Chemistry Award of the Spanish Royal Society of Chemistry, and the Theodor Förster Award of the German Chemical Society and the Bunsen Society of Physical Chemistry. He has been the President of the European Society for Photobiology from 2009 to 2011. 


\section{Photograph of the group}

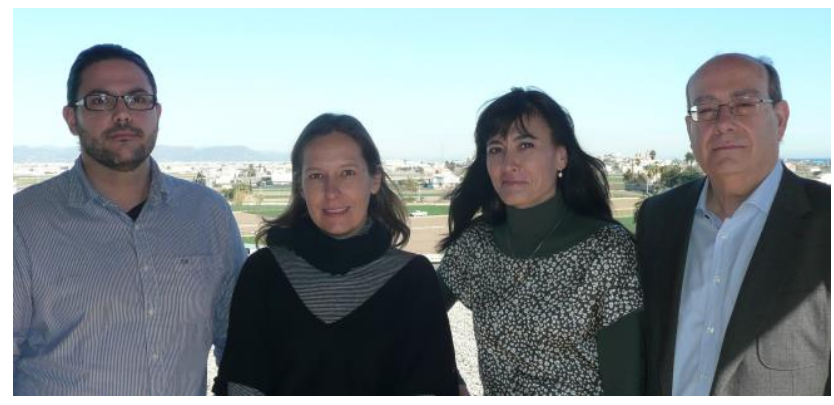

From left to right: Ignacio Vayá, Virginie Lhiaubet-Vallet, M. Consuelo Jiménez and Miguel A. Miranda 


\section{Table of Contents}

Modification of the drug excited state properties within proteins provides information on binding and may result in a different photoreactivity.

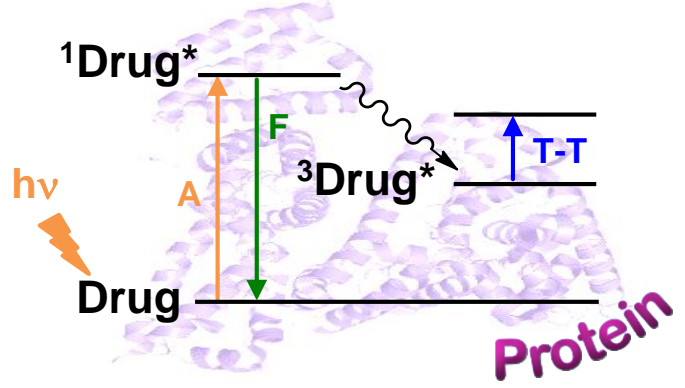

